Florida International University FIU Digital Commons

\title{
Desperate Housewives? Communication Difficulties and the Dynamics of Marital (un)Happiness
}

Peter Thompson

Department of Economics, Florida International University, thompsop@fiu.edu

Follow this and additional works at: https://digitalcommons.fiu.edu/economics_wps

\section{Recommended Citation}

Thompson, Peter, "Desperate Housewives? Communication Difficulties and the Dynamics of Marital (un)Happiness" (2007). Economics Research Working Paper Series. 66.

https://digitalcommons.fiu.edu/economics_wps/66 


\title{
Desperate Housewives?
}

\section{Communication Difficulties and the Dynamics of Marital (un)Happiness}

\author{
Peter Thompson \\ Florida International University
}

February 2006

This revision: July 2007

\begin{abstract}
This paper develops a model of marital dissolution based on communication difficulties. The quality of a marriage depends on the proximity of an action to a target. The target is unknown, and must be learned over time. Each individual receives private signals about the target, and can communicate them only imperfectly to his or her spouse. Because of imperfect communication, spouses may hold different beliefs about the optimal action. The action actually chosen is a compromise of the spouses' distinct beliefs. If a couple's beliefs diverge too widely, one or both of them may prefer to dissolve the marriage. The paper explores how poor communication contributes to marital unhappiness, as well as its implications for the dynamics of divorce risk, the welfare properties of divorce decisions, and the role of counseling. When the distribution of decision-making power in the household favors men, wives (but not husbands) can find themselves trapped for prolonged periods in a marriage that leaves them as unhappy as it is possible to be without seeking relief through divorce.
\end{abstract}

JEL Classifications: J12, D1, D79, D83.

Keywords: Marriage, divorce, communication difficulties, learning.

\footnotetext{
* Department of Economics, Florida International University, Miami, FL 33199, email: peter.thompson2@fiu.edu. Support from the College of Arts \& Sciences Summer Research Fund, Florida International University, is gratefully acknowledged. I am grateful for helpful comments from my wife, few of which I understood.
} 


\title{
I. Introduction
}

\author{
The marriage guidance counselor told the couple, "It is essential that husbands \\ and wives know the things that are important to each other." He addressed the \\ husband, "Do you know what your wife's favorite flower is?" "Of course," the hus- \\ band replied, "Pillsbury All-Purpose."
}

This paper develops a model of marital dissolution based on communication difficulties. The quality of a marriage depends on the proximity of an action, $x$, to a target $\theta$. The target is unknown, and must be learned over time. Each individual receives private signals about $\theta$, and can communicate them only imperfectly to his or her spouse. Because of imperfect communication, spouses may hold different beliefs about the optimal action. The action actually chosen is therefore a compromise of the spouses' distinct beliefs. If a couple's beliefs diverge too widely, one or both of them may prefer to dissolve the marriage.

The existing economics literature has little to say about communication and divorce. Most of the literature on long-term relationships has, since Becker's [1973, 1974] seminal work, been concerned with partnership formation, especially the conditions required for assortative matching (see Burdett and Coles [1999] for a review), in a world characterized by exogenously heterogeneous match quality. The literature on the dissolution of partnerships has grown out of this framework and, as a result, is quite narrow in scope. In studies that tackle divorce, marriages are either objectively good or bad, relative to outside opportunities. There does not seem to be any place in this literature for resolving difficulties in a marriage as an alternative to divorce. Yet this is what we see many couples doing, either on their own or with the help of counseling.

This paper is intended to fill this gap in the literature by constructing a model in which all matches are ex ante identical, and evolving communication difficulties are the only source of marital discord. There is extensive evidence pointing toward the central role of affective issues, certainly in absolute terms, and likely also relative to economic concerns. Wolcott and Hughes [1999: Tables 10 and 11] report that women were six times more 
likely and men five times more likely to cite affective issues over external (including economic) factors as the main reason for divorce. While it is true that income instability and other economic variables are known to influence marital stability, the effects seems to be relatively small (Gottman [1994]). For example, in an exhaustive meta analysis of 115 longitudinal studies, the estimated aggregate effect size of "positive behavior" was found to be four times that of the positive effect of increasing husband's income and ten times the size of the negative effect of increasing wife's income (Karney and Bradbury [1995]). ${ }^{1}$

Among affective factors, there is also considerable evidence identifying difficulties communicating as a major cause of marital failure, whether measured by divorce probability or by expressions of distress within the marriage. In a longitudinal study of 40 young couples, Storaasli and Markman [1990] found that the quality of communication was, along with money, one of the two most important determinants of marital satisfaction out of ten considered. Miller et al. [2003] obtained exactly the same ranking of problem areas, out of fourteen considered, in a clinical setting of relatively young couples. Whisman, Dixon and Johnson [1997] surveyed 500 therapists working with couples, and found that communication difficulties was the most commonly presented problem. In a largescale longitudinal study, Amato and Rogers [1997] found that reports of communication difficulties were a significant predictor of divorce twelve years hence. Communication difficulties appear to become less important with time, but continue to dog even mid-life couples (Levenson, Carstensen and Gottman [1993]; Henry and Miller [2004]).

\section{A. Main Results}

The model is used to explore the dynamics of disagreement and divorce, to examine the welfare properties of private decisions about divorce, and the role of interventions such as counseling. The hazard rate of divorce initially rises with marriage tenure before falling to zero, consistent with the evidence (inter alia, Wiess and Willis [1997]). The model shows

1. Of course, income instability may reduce the prevalence of positive behaviors, so that part of the effect size attributed to behavior has income instability as its root cause. Amato [1996] and Karney and Bradbury [1995] argue that the effects of many socio-demographic factors are likely mediated through behavioral changes, including patterns of communication and conflict. 
how poor communication contributes to marital instability, and predicts that the hazard of divorce increases with the degree of uncertainty about the target and with signal noise only when there are communication problems. Some marriages are more difficult than others, but only communication difficulties make them untenable.

The welfare implications of our model depend upon why communication difficulties occur, and whether we assume symmetry between spouses. Communication difficulties can arise simply because it is difficult to observe and communicate utility functions, and individuals know that they observe signals about their spouse's utility imperfectly. In this case, and under symmetry, divorce is always mutually agreeable and it is optimal, both from the perspective of social welfare and from the perspective of the welfare of spouses contemplating divorce. ${ }^{2}$ Communication difficulties may also arise because individuals are solipsistic. That is, they believe their own signals to be more accurate than their spouse's signals. In this case, again under symmetry, we find that divorce decisions are not optimal. Solipsists may be either too quick or too slow to divorce, depending on the form that solipsism takes. ${ }^{3}$

In practice, however, marriages are unlikely to involve symmetry. In fact the evidence suggests that women are better listeners and communicators, they are more likely to be able to explain the cause of marital failure, and they are more likely to express concerns about the inequitable distribution of decision-making power in the household (Dowling and Flint [1990], Hawkins, Weisberg and Ray [1980], Infante and Rancer [1982]). Unsurprisingly, married women are usually less happy than their husbands (Komorovsky [1964]) and they are much more likely to seek divorce (Brining and Allen [2000]). Moreover, when divorce laws have been altered to allow one partner to leave over the objections of the other, suicide rates have fallen for women but not men (Stevenson and Wolfers [2006]). We therefore also analyze an asymmetric case in which decisions made by the

2. Because the focus of this paper is on the welfare and policy implications of communication difficulties, I assume the matching rate for singles is homogeneous of degree zero in the number of single men and women.

3. The notion of solipsism and the evidence for it will be presented in section II. It is convenient therefore also to postpone discussion of the intuition behind this welfare result. 
household are biased towards the husband's beliefs about the target. In this setting, the wife is the first to select divorce and, because at that time the husband prefers continuation, divorce rates exceed the social optimum.

In many traditional models, there is a Coasian solution to the inefficiency of divorce under asymmetry, in which one spouse irrevocably transfers wealth to the other to prevent divorce (Becker [1973]). An analogy exists in the present model, whereby the husband offers to forego part of his control over household decision-making, to compensate his wife for foregoing divorce. However, husbands cannot commit to future behavior, and offers to alter behavior for the future are time-inconsistent. The best a husband can promise to an unhappy wife on the verge of divorce is to keep her, for perhaps a considerable time into the future, as miserable as she is today. These are the desperate housewives of the title; their only weapon to improve their lot in marriage is to increase the value of divorce by inter alia improving employment prospects, opening secret bank accounts, or initiating extramarital relationships. ${ }^{4}$

The model also provides an explicit productive role for marriage guidance counseling, if it is intended to improve communication between spouses. The model predicts that counseling is more valuable, and hence more likely to be chosen instead of immediate separation, for couples with longer marriage duration. The model also predicts that a possibly sizable fraction of couples that successfully avoid separation through counseling today will again find themselves in crisis at a later stage, and that this is more likely to happen for younger couples.

\section{B. Comparison with Existing Theory}

This paper is intended as a complement to, rather than a substitute for, models with heterogeneous match quality. But it is useful to take a moment to compare the two frameworks. In the traditional model, individuals are distinguished by some observable characteristics that define their type. A marriage is formed to produce public and private goods

4. Glass and Wright [1985] report that women are more likely than men to embark upon an extramarital affair as a result of marital dissatisfaction, and they are more likely to pursue long-term emotional relationships. 
and services, with output governed by a production function in which productivity depends upon individual types and that exhibits complementarity between types. In both frictionless and search models of marriage, this complementarity induces positive assortative matching. Divorce may arise through any of three mechanisms. First, search for better partners may continue during marriage, and divorce is elected when a better match is found (Becker, Landes and Michael [1977], Mortensen [1988], Cornelius [2003]). Second, types may only be observable with noise, and married partners learn the true quality of the match only with the passage of time; they divorce when the perceived quality of the match falls below a critical level (Jovanovic [1979], Bougheas and Georgellis [1999]). ${ }^{5}$ Third, the quality of the match may change as the result of unanticipated shocks (Becker, Landes and Michael [1977], Weiss and Willis [1997]), or purposive investments in marriage-specific capital. ${ }^{6}$

The obvious contrast between the traditional framework and the present model is that in the latter all individuals and marriages are ex ante identical. Nonetheless, the quality of each marriage evolves along a unique path as disparate private signals induce disagreements. Given sufficient time, all disagreements will eventually be resolved; but they are long-lived and significant disagreement drives the quality of a marriage below the critical threshold that induces divorce.

The present model therefore blends characteristics of the second and third mechanisms for divorce in the traditional model. Not surprisingly, it also shares several predictions with these mechanisms. ${ }^{7}$ Two examples suffice to illustrate. Consider first the hazard of divorce. In Jovanovic's [1979] model of learning about match quality, separation is determined by the first-passage of a standard diffusion process to a single barrier that is moving away from the origin as a linear function of time. In the present model, it is gov-

5. This model was first analyzed formally by Jovanovic in the context of labor markets.

6. There is of course more to the traditional framework than this précis suggests, and it is not my intention to discount this extensive body of work. Thorough reviews can be found in Weiss [1997, forthcoming].

7. One might view this as a weakness of the present model; however, as these common predictions are evident in the data, they are also a constraint that binds on any new theory of divorce. 
erned by the first passage of a standard diffusion process to either of two linear barriers, symmetric around the origin, that are moving away from the origin. These two optimal stopping problems yield different distributions of stopping times, but the qualitative properties of the corresponding hazard are essentially the same: the hazard rises sharply to a unique mode, before declining more gradually, asymptotically approaching zero.

Second, both models admit reasonable conditions under which positive shocks to a husband's income reduce the divorce hazard, while positive shocks to the wife's income raise it. This is exactly what the data show (Becker, Landes and Michael [1977], Greenstein [1990], Weiss and Willis [1997]). However, the mechanisms in the two models are very different. In the traditional model, there is asymmetry between men and women in the labor market, with women more likely to specialize in home production, or work part time. As a consequence, positive shocks to men's incomes increase the gains from marriage, while positive shocks to women's incomes reduce the gains. In the present model, positive shocks to either partner's income make divorce more attractive for them, and less attractive for their partner. When the household action favors husbands' preferences, only the wife is near the threshold that makes divorce the preferred option. A positive shock to her income may push her over the threshold, while a positive shock to her husband's income moves the threshold further away. ${ }^{8}$

There are also distinctions. Traditional models have no obvious role for counseling; the present model has nothing to say about sorting. These are, perhaps, not especially important distinctions: modest extensions to either model would eliminate the deficiencies. ${ }^{9}$

8. If one were to insist on mutually exclusive theories, these distinct mechanisms behind the effects of income shocks generate a discriminating test. The traditional model predicts the indicated effects of income shocks should hold only for couples in which the wife has specialized (relatively) in household production, while the present model predicts it should hold for all marriages.

9. For example, one can take a broad view of the production function in the traditional model to include intangible outputs such as companionship. Counseling may then help couples make marriage-specific investments to increase the output of these intangibles. In the present model, individuals may be allowed to differ in their ability to communicate, the accuracy of their signals or the 


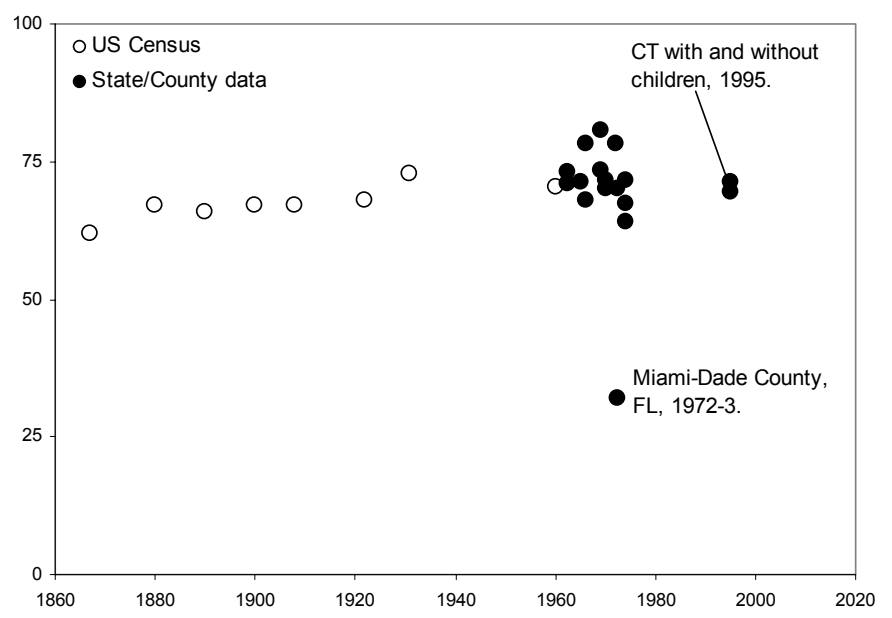

FIGURE 1. Proportion of divorces applications filed by women. Soruce: Birnig and Allen [2000]

However, there is one important phenomenon that the present model does much to explain, but which is a challenge for the traditional theory: women instigate the majority of divorces and separations. For example, in a study of 48,000 cases from four states that record the initiator of divorce proceedings, Brinig and Allen [2000] report that the proportion of divorces initiated by women has consistently exceeded 70 percent since no-fault divorce was introduced in the late 1960s. In fact, as Figure 1 shows, women have initiated the majority of divorce proceedings in the United States at least since the Civil War. That they are willing to do so in the face of impending economic hardship, and that they are more likely than men to report ex post that divorce was the correct decision strikes Brinig and Allen [2000] as a puzzle for traditional economic models. The framework developed in this paper may provide a solution to this puzzle.

accuracy of their prior beliefs. There then emerges a complementarity that would induce positive sorting along these intangible dimensions. 


\section{The model}

A marriage consists of two individuals, traditionally denoted $m$ and $f$, who begin cohabitation at time 0 . Let $u_{i t}, i=\{m, f\}$, which denotes the flow of utility earned by married individual $i$ in period $t$, satisfy

$$
u_{i t}=-\left(\theta-x_{t}+\zeta_{i t}\right)^{2} \text {, }
$$

where $\theta$ is an unknown target, $x_{t}$ is an action chosen by the couple, and $\zeta_{i t}$ is an individual shock. The parameter $\theta$ is assumed at time 0 to be a random draw from $N\left(0, \sigma_{\theta}^{2}\right)$, while the individual shocks are i.i.d draws from $N\left(0, \sigma_{i}^{2}\right)$. Individual $i$ observes $u_{i t}$ precisely in each period, and observes his or her partner's utility with noise. It is convenient to as-

sume that $i$ observes $\tilde{u}_{j t}=-\left(\theta-x_{t}+\left(\zeta_{j t}+\varepsilon_{j t}\right)\right)^{2}$ for $j \neq i$, where $\varepsilon_{j} \sim N\left(0, s_{j}^{2}\right)$. The action chosen in each period is of course directly observable, Hence, observation of the sequences of payoffs $u_{i s}$ and $\tilde{u}_{j s}, s=0,1,2, \ldots, t-1$, is equivalent to having observed $t$ normally distributed signals with mean $\theta$ and variance $\sigma_{i}^{2}$, and another $t$ independent signals with mean $\theta$ and variance $\sigma_{j}^{2}+s_{j}^{2}$. Standard Bayesian formulae for normal conjugates then imply that $i$ 's expectation of the target is

$$
E_{i t}(\theta)=\frac{\sigma_{\theta}^{2}\left(\gamma_{j} y_{i t}+y_{j t}\right)}{\left(\gamma_{j}+1\right) t \sigma_{\theta}^{2}+\gamma_{j} \sigma_{i}^{2}},
$$

with posterior variance

$$
\sigma_{i t}^{2}=\frac{\gamma_{j} \sigma_{\theta}^{2} \sigma_{i}^{2}}{\left(\gamma_{j}+1\right) t \sigma_{\theta}^{2}+\gamma_{j} \sigma_{i}^{2}}
$$

where $\gamma_{j}=\left(\sigma_{j}^{2}+s_{j}^{2}\right) / \sigma_{i}^{2}$, and $y_{i t}=\theta t+\sum_{\tau=0}^{t-1} \zeta_{i \tau}$. Given these beliefs, $i$ believes the optimal action is $x=E_{i t}(\theta)$. The action actually chosen by the couple is $x_{t}=\bar{\theta}_{t}=\phi_{m} E_{m t}(\theta)+\left(1-\phi_{m}\right) E_{f t}(\theta)$, where the parameters $\phi_{m}$ and $\phi_{f}=1-\phi_{m}$ capture the distribution of decision-making power within the household.

A higher variance, $\sigma_{i}^{2}$, affects the payoffs in two ways. First, it makes it harder for both spouses to learn $\theta$, so that actions are likely to be further from optimal and the payoff is 
reduced. Second, for any given action, a higher variance directly reduces expected utility for spouse $i$, because $u$ is concave. The variance $\sigma_{i}^{2}$ is consequently a measure of the quality of the marriage. In this paper, it is assumed that $\sigma_{i}^{2}$ is known. Assuming instead that $\sigma_{i}^{2}$ is initially unknown and must be slowly learned over time lays the foundation for a model with heterogeneous marriage quality in the presence of communication difficulties.

Deviations of the parameters $\gamma_{m}$ and $\gamma_{f}$ from unity measure the extent of communication difficulties. It will be immediately clear in what follows that we require $\gamma_{i} \neq 1$ for at least one of $m$ or $f$. Otherwise, they would always be in agreement about the optimal action. We have in mind a situation in which individuals pay too little attention to their spouses' signals, either because they are difficult to observe, or because spouses choose not to observe them. However, disagreements will also arise if individuals pay too much attention to their spouse, in the sense that they think their spouse's signals are more accurate than they really are. The intuition is simple: $i$ tells $j$ his noisy signal, and $j$ overreacts to it, believing it to be accurate (and vice-versa). It's the "[s] he takes everything I say too literally" complaint.

Two remarks are in order here. First, one might imagine that the distribution of decisionmaking power within the household would be determined through some bargaining process. If so, one might expect $\phi_{m}$ and $\phi_{f}$ not to be exogenous parameters, but to depend on characteristics of the marriage market yet to be discussed (cf. Manser and Brown [1980], McElroy and Horney [1981], Lundberg and Pollack [1993]). This paper abstracts from such issues to focus on the mechanics of communication difficulties and marital quality. It does seem at this stage, as the profession is only just beginning to grapple with emotion and affective issues (e.g. Elster [1998], Loewenstein [2000]), that our standard tools for analyzing bargaining would bring little insight.

Second, spouses presumably must reveal their posterior means to each other in order to arrive at a compromise decision. But this revelation also allows each spouse to infer precisely the other's private signals. If each spouse efficiently incorporates these signals into his or her own beliefs, the revised posterior mean will then be the same for both spouses. But then, communication difficulties (as measured by $\gamma$ ) would be neutralized, and disagreement would be impossible. More generally, Aumann [1976] has shown that if the posteriors of two Bayesians with common priors are common knowledge, these posteriors 
must be the same; Geanakoplos and Polemarcharkis [1982] show further that if two agents with common priors exchange their efficient posteriors back and forth they will arrive at the common knowledge posterior.

These results leave two ways in which disagreements can persist. First, one can drop the efficiency of individuals' updating algorithms. Second, one can drop the common prior assumption. The posterior beliefs given in (2) and (3) are on their face derived by taking the first approach. But one can also obtain them from an assumption that follows the second. Disagreement arises when individuals believe their own signals to be more accurate than their partner's. Klepper and Thompson (2006) have called this asymmetric treatment of signals solipsism and explored its implications for the formation of new firms. Solipsism may arise because individuals overestimate the accuracy of their own signals (this case has often been referred to as overconfidence), or underestimate the accuracy of other people's signals. ${ }^{10}$ In either type of solipsism, it does not matter that spouses observe each other's posterior beliefs, because they each maintain the assumption that their spouse is mistaken.

\section{A. Equal Partnerships}

To begin, symmetry between spouses is imposed. Let $\phi_{f}=\phi_{m}=1 / 2$. Let $\sigma_{m}^{2}=\sigma_{f}^{2}=\sigma_{\zeta}^{2}$, so that the "quality" of marriage is equal for the two. Let $s_{m}^{2}=s_{f}^{2}$, so that failures of com-

10. There is a large empirical literature supporting the assumption of overconfidence and, to a lesser extent, the more general notion of solipsism. De Bondt and Thaler [1995] have gone so far as to claim that "perhaps the most robust finding in the psychology of judgment is that people are overconfident." Evidence of overconfidence has been reported among diverse professions, including entrepreneurs (Cooper, Woo, and Dunkelberg [1988]) and managers (Russo and Schoemaker [1992]), although entrepreneurs exhibit much more overconfidence than managers (Busenitz and Barney [1997]). Odean [1998] and Daniel, Hirshleifer, and Subrahmanyam [1998] cite many other examples, and different forms of overconfidence. Our assumption that individuals overweight private information relative to "public" information has found support in the laboratory (Anderson and Holt [1996]) and among financial analysts (Chen and Jiang [2003]). Their findings are consistent with the broader notion that people expect good things (e.g. receiving accurate signals) to happen to them more often than they do to others (Weinstein [1980], Kunda [1987]). 
munication are the same in both directions. Then, $\gamma_{m}=\gamma_{f}=\gamma$ and $\sigma_{m t}^{2}=\sigma_{f t}^{2}=\sigma_{t}^{2}$. Let $\Delta_{i t}=E_{i t}(\theta)-\bar{\theta}_{t}$ denote $i$ 's disagreement with the joint action. Imposing symmetry in (2) yields

$$
\Delta_{i t}=\frac{(\gamma-1) \sigma_{\theta}^{2}}{2\left((\gamma+1) t \sigma_{\theta}^{2}+\gamma \sigma_{\zeta}^{2}\right)}\left(y_{i t}-y_{j t}\right) .
$$

The random variables $y_{i t}$ and $y_{j t}$ are normally distributed and independent, each with (unknown) mean $\theta t$ and (true) variance $t \sigma_{\zeta}^{2}$. Thus, $\Delta_{i t}$ is normal with mean zero and variance

$$
\operatorname{var}\left(\Delta_{i t}\right)=\frac{(\gamma-1)^{2} t \sigma_{\theta}^{4} \sigma_{\zeta}^{2}}{2\left((\gamma+1) t \sigma_{\theta}^{2}+\gamma \sigma_{\zeta}^{2}\right)^{2}}
$$

Because of the imposed symmetry, the disagreements of husband and wife with the joint action are related by $\Delta_{f t}=-\Delta_{m t}$. In a symmetric equilibrium, the value of the outside option will also be the same. Thus, both will elect divorce at the same time, and we can consider the evolution of (4) as the stochastic process that governs marriage duration.

Given the joint decision and beliefs at time $t$, individual $i$ 's expected utility is

$$
\begin{aligned}
E_{i t}(u) & =-E_{i t}\left[\left(\theta-\bar{\theta}_{t}-\zeta_{i t}\right)^{2}\right] \\
& =-E_{i t}\left[\left(\left(\theta-E_{i t}(\theta)\right)+\left(E_{i t}(\theta)-\bar{\theta}_{t}\right)-\zeta_{i t}\right)^{2}\right] \\
& =-\left(\sigma_{i t}^{2}+\Delta_{i t}^{2}+\sigma_{\zeta}^{2}\right) \\
& =-\sigma_{\zeta}^{2}\left(1+\frac{\gamma \sigma_{\theta}^{2}}{(\gamma+1) t \sigma_{\theta}^{2}+\gamma \sigma_{\zeta}^{2}}\right)-\Delta_{i t}^{2} .
\end{aligned}
$$

The first term reflects the increasing precision of the posterior distribution of the target. Because we have assumed a normal prior and normal signals, this term is deterministic and monotonically increasing in $t$. The term $\Delta_{i t}^{2}$ is the cost, in terms of foregone expected utility, of the current disagreement between spouses. It is zero at $t=0$, but then becomes positive before eventually returning to zero asymptotically. The second term is 
of course stochastic and may rise and fall several times before approaching zero as marriage tenure rises.

Equation (6) shows that the one-step ahead expectation of utility may rise and fall over time with the evolution of disagreements. But it is possible that communication difficulties have an even stronger effect on expectations. At the time of marriage, the belief an individual has about utility in some future period $t$ is given by:

$$
\begin{aligned}
E_{i 0}\left(u_{t}\right) & =E_{i 0}\left[E_{i t}(u)\right] \\
& =-\sigma_{\zeta}^{2}\left(1+\frac{\gamma \sigma_{\theta}^{2}}{(\gamma+1) t \sigma_{\theta}^{2}+\gamma \sigma_{\zeta}^{2}}\right)-E_{i 0}\left[\Delta_{i t}^{2}\right] \\
& =-\sigma_{\zeta}^{2}\left(1+\frac{\gamma \sigma_{\theta}^{2}}{(\gamma+1) t \sigma_{\theta}^{2}+\gamma \sigma_{\zeta}^{2}}\right)-\frac{(\gamma-1)^{2} t \sigma_{\theta}^{4} \sigma_{\zeta}^{2}}{2\left((\gamma+1) t \sigma_{\theta}^{2}+\gamma \sigma_{\zeta}^{2}\right)^{2}} E\left[\chi_{1}^{2}\right] \\
& =-\sigma_{\zeta}^{2}\left(1+\frac{\gamma \sigma_{\theta}^{2}}{(\gamma+1) t \sigma_{\theta}^{2}+\gamma \sigma_{\zeta}^{2}}\right)-\frac{(\gamma-1)^{2} t \sigma_{\theta}^{4} \sigma_{\zeta}^{2}}{2\left((\gamma+1) t \sigma_{\theta}^{2}+\gamma \sigma_{\zeta}^{2}\right)^{2}} .
\end{aligned}
$$

When $\gamma=1$, so there are no communication problems, every spouse expects next period to be better than this period: on average marriages without communication problems improve monotonically. Communication problems eliminate this comforting projection, and some spouses, especially those in marriages with poor communication, may from the start expect things to get worse before they get better. Recent empirical evidence suggests this pessimistic projection is warranted. In longitudinal data spanning 17 years, Stutzer and Frey [2003] show that the average self-assessment of happiness declines monotonically for a decade after marriage.

Let $v$ denote the value of being single, $k$ the cost of divorce, and let $V\left(\Delta_{t}^{2}, t ; v-k\right)$ denote the value at time $t$ of having a difference of opinion of size $\Delta_{t}^{2}$. Each spouse faces the following optimal stopping problem:

$$
\begin{aligned}
V\left(\Delta_{t}^{2}, t ; v-k\right)=\max \{v-k, & -\sigma_{\zeta}^{2}\left(1+\frac{\gamma \sigma_{\theta}^{2}}{(\gamma+1) t \sigma_{\theta}^{2}+\gamma \sigma_{\zeta}^{2}}\right)-\Delta_{t}^{2} \\
& \left.+\beta \int V\left(\Delta_{t+1}^{2}, t+1 ; v-k\right) d F\left(\Delta_{t+1}^{2} \mid \Delta_{t}^{2}, t\right)\right\} .
\end{aligned}
$$


In each period, the spouse may elect divorce and receive the payoff $v-k$, or continue in the marriage. Continuation yields a payoff consisting of two parts. The first is the oneperiod utility received from the marriage. The second is the expected value of remaining married at the beginning of the next period, with a discount factor of $\beta$, and where expectations are taken over the possible values of $\Delta_{t+1}^{2}$. The distribution of $\Delta_{t+1}^{2}$, $F\left(\Delta_{t+1}^{2} \mid \Delta_{t}^{2}, t\right)$, depends on the current disagreement size as well as the tenure of marriage. ${ }^{11}$

It is shown in the appendix that $V\left(\Delta_{t}^{2}, t ; v-k\right)$ is decreasing in $\Delta_{t}^{2}$, and this is the key result that ensures the solution to (8) is typical of most stopping problems:

Proposition 1. The optimal stopping problem has a unique solution, $D_{t}^{2}$, such that continuation is optimal if $\Delta_{t}^{2}<D_{t}^{2}$ and divorce is chosen whenever $\Delta_{t}^{2}>D_{t}^{2}$.

Proof. See Appendix.

In the absence of a divorce option, it is easy to establish that $V\left(\Delta_{t}^{2}, t\right)$ is linear in $\Delta_{t}^{2}$. Hence, as a well-known property of optimal stopping problems with compact continuation regions, we have the following result:

Proposition 2. $V\left(\Delta_{t}^{2}, t ; v\right)$ is a convex function of $\Delta_{t}^{2}$.

ProOF. See Appendix.

At the boundary of the stopping problem, the reservation equation is (see Appendix)

$$
(1-\beta)(v-k)=E_{t}\left(u\left(D_{t}^{2}, t\right)\right)-\beta \int_{0}^{D_{t+1}^{2}} V_{\Delta^{2}}\left(\Delta_{t+1}^{2}, t+1 ; v-k\right) F\left(\Delta_{t+1}^{2} \mid D_{t}^{2}, t\right) d \Delta_{t+1}^{2}>0,
$$

where $V_{\Delta^{2}}=\partial V / \partial \Delta_{t+1}^{2} \leq 0$. The term $(1-\beta)(v-k)$ is the annuitized opportunity cost of remaining in the marriage. The integral expression on the right is the option value of remaining in the marriage, which may yield a smaller disagreement and therefore higher

11. The exact distribution is derived in Lemma 1 in the Appendix. 
utility in the next period. Spouses remain together even though doing so provides a lower utility flow than getting divorced, in the hope that the marriage will soon become better.

To evaluate the outside option, we characterize the market for singles in a very simple way. Let $V(0,0, v)$ denote the value of a new marriage, and let $\lambda$ denote the per-period utility earned while single. Assume a population of infinitely-lived individuals, evenly divided between men and women. In each period single individuals meet a potential partner with probability $\mu$. All potential partners are equally attractive, so every meeting produces a marriage at the beginning of the next period. Hence, the value of being single is $v=\lambda+\beta(\mu V(0,0 ; v)+(1-\mu) v)$. For marriage to be attractive to single people, we require that $v<V(0,0 ; v-k)$ or, equivalently, that $\lambda<(1-\beta) V(0,0 ; v-k)$.

This simple characterization eliminates a key externality found in some previous marriage models. In those models, individuals mix randomly without regard to marital status, so the probability that a single individual meets another single is increasing in the fraction of the population that is unmarried. Increasing returns in the matching function induces a market failure because individuals consider divorce without taking into account the contribution that their divorce would make to the welfare of other singles (e.g. Chiappori and Weiss [2003]). Although random mixing is a more realistic representation, we will maintain our simple characterization of the singles market in order to focus on the consequences of communication difficulties.

The boundary, $D_{t}^{2}$, may rise or fall over time in a way that defeats explicit analysis. On the one hand, any given size of disagreement is associated with greater one-period utility as $t$ rises. This will cause the size of disagreement necessary to induce divorce to rise over time. On the other hand, the option value of remaining in the marriage declines with time because the variance of $\Delta_{t+1}^{2}$ conditional on $\Delta_{t}^{2}$ declines with $t$. This effect induces a decline in the size of disagreement necessary to induce divorce. ${ }^{12}$ It does not seem to be

12. When $t$ is small, the conditional variance of $\Delta_{t+1}^{2}$ is large, so there are considerable opportunities to see an improvement in the state variable next period. Hence, the option value of remaining in the marriage is greater. But at $t$ rises, it becomes less likely that $\Delta_{t+1}^{2}$ will be much less than $\Delta_{t}^{2}$. 
possible to show that one of these effects dominates the other, which creates difficulties for studying the hazard of divorce as a function of marriage duration.

In a related labor turnover model, Jovanovic [1979] offers an approximate solution to the hazard problem by fixing the critical value for dissolution of the match to its asymptotic value. Adapting Jovanovic's strategy here requires setting $D_{t}^{2}=\lim _{t \rightarrow \infty} D_{t}^{2}$ for all $t$. For large $t$, we have $\lim _{t \rightarrow \infty} \Delta_{t+1}^{2}=\Delta_{t}^{2},{ }^{13}$ and the second term on the right hand side of (9) becomes $-\beta V_{\Delta^{2}}\left(D_{t}^{2}, t+1 ; v-k\right)=-\beta V_{\Delta^{2}}\left(D_{t}^{2}, t ; v-k\right)=0$. The first equality arises because there is no further evolution in $F$, and the second equality is due to the usual smoothpasting condition at the boundary. Thus, $\lim _{t \rightarrow \infty} D_{t}^{2}=-\sigma_{\zeta}^{2}-(1-\beta)(v-k)$.

The approximation strategy therefore requires the distribution of the Markov time, $T$, that satisfies

$$
T=\min _{\tau}\left\{\tau:\left|\Delta_{\tau}\right| \geq \sqrt{-\sigma_{\zeta}^{2}-(1-\beta)(v-k)}\right\}
$$

This first passage problem is easier to analyze in the continuous-time analog to our problem (c.f. Cox and Miller [1965]). Define

$$
\omega_{t}=\sqrt{2}\left(\frac{(\gamma+1) t \sigma_{\theta}^{2}+\gamma \sigma_{\zeta}^{2}}{(\gamma-1) \sigma_{\theta}^{2} \sigma_{\zeta}}\right) \Delta_{t} .
$$

The random variable $\omega_{t}$ is normal with zero mean and variance $t$, while the increments to $\omega_{t}$ are independent standard normals. The continuous time stochastic process $d \omega(t)$ that gives rise to the same distribution as $\omega_{t}$ at $t=0,1,2, \ldots$, is a standard zero-drift Wiener process with boundary condition $\omega(0)=0$.

Let $\left|\Delta^{*}\right|=\sqrt{-\sigma_{\zeta}^{2}-(1-\beta)(v-k)}$, and let $\left|\omega^{*}(t)\right|$ denote the corresponding absolute value of $\omega^{*}$ evaluated at time $t$. From (11)

$$
\left|w^{*}(t)\right|=\frac{\sqrt{2}\left|\Delta^{*}\right| \gamma \sigma_{\zeta}}{(\gamma-1) \sigma_{\theta}^{2}}+\frac{\sqrt{2}\left|\Delta^{*}\right|(\gamma+1) t}{(\gamma-1) \sigma_{\zeta}^{2}}
$$

13. Although it should be understood that $\lim _{t \rightarrow \infty} \operatorname{Pr}\left\{\Delta_{t}^{2}>0\right\}=0$. 


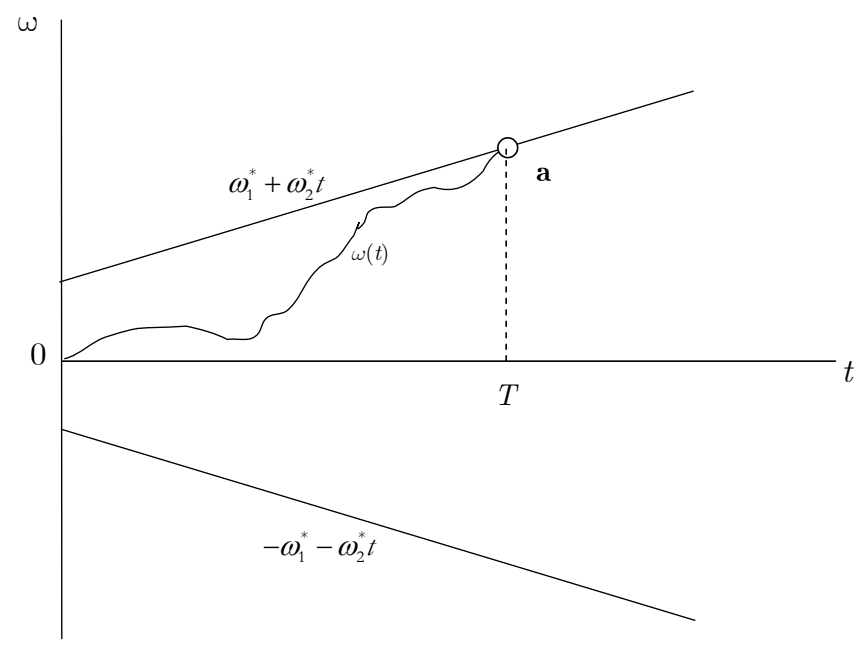

FIGURE 2. The first passage problem for marital dissolution

$$
\equiv \omega_{1}^{*}+\omega_{2}^{*} t
$$

Equations (11) and (12) define the problem for the first passage of a Wiener process to either of two linear boundaries, $\omega_{1}^{*}+\omega_{2}^{*} t$ and $-\omega_{1}^{*}-\omega_{2}^{*} t$, that are moving away from the origin (see Figure 2). This transformation of the problem enables us to exploit some known results on first passage times.

TheOrem 1 (Doob [1949]). Let $F\left(T \mid \omega_{1}^{*}, \omega_{2}^{*}\right)$ denote the distribution of first passage times for (11) and (12). Then $\lim _{t \rightarrow \infty} F\left(T \mid \omega_{1}^{*}, \omega_{2}^{*}\right)=\sum_{n=1}^{\infty}(-1)^{n+1} e^{-2 \omega_{1}^{*} \omega_{2}^{*} n^{2}}$.

Theorem 1 gives the probability that a couple ever divorces. The next proposition establishes that, for any parameter configuration, there is a strictly positive probability that a marriage never results in divorce.

Proposition 3. For any $\omega_{1}^{*}>0, \omega_{2}^{*}>0, \lim _{t \rightarrow \infty} F\left(T \mid \omega_{1}^{*}, \omega_{2}^{*}\right)<1$.

PROOF. Let $x_{n}=(-1)^{n+1} e^{-2 \omega_{1}^{*} \omega_{2}^{*} n^{2}}$ and $s_{k}=\sum_{n=1}^{k} x_{n}$. We have $\lim _{k \rightarrow \infty}\left|s_{k}\right|<\sum_{n=1}^{\infty} e^{-2 \omega_{1}^{*} \omega_{2}^{*} n}=$ $2\left(e^{2 \omega_{1}^{*} \omega_{2}^{*}}-1\right)^{-1}<\infty$, so the series is absolutely convergent. Note also that $\left|x_{n+1}\right|<\left|x_{n}\right| \forall n$, 
and $x_{1}>0$. Hence, using a well-known property of alternating series, $\lim _{t \rightarrow \infty} F\left(T \mid \omega_{1}^{*}, \omega_{2}^{*}\right)$ $\leq x_{1}=e^{-2 \omega_{1}^{*} \omega_{2}^{*}}<1$.

As

$$
\omega_{1}^{*} \omega_{2}^{*}=\frac{2\left((1-\beta)(k-v)-\sigma_{\zeta}^{2}\right) \gamma(\gamma+1)}{(\gamma-1)^{2} \sigma_{\theta}^{2}}
$$

and $\lim _{t \rightarrow \infty} F\left(T \mid \omega_{1}^{*}, \omega_{2}^{*}\right)$ is decreasing in $\omega_{1}^{*} \omega_{2}^{*}$, it is easy to identify factors that raise the probability that a marriage ends in divorce.

Proposition 4. Marriages are more likely to end in divorce (i) the greater the difficulty communicating preferences $(\lambda)$, (ii) the larger the prior uncertainty about the target $\left(\sigma_{\theta}^{2}\right)$, (iii) the noisier the signals $\left(\sigma_{i}^{2}\right)$, (iv) the lower the divorce costs $(k)$, and, (v) the greater the value of being single $(v)$.

These results are intuitive and need no further explanation. However, the likelihood of marital failure as a function of $\gamma$ is of particular interest, and this relationship is plotted in Figure 3. No marriage fails if $\gamma=1$; the divorce probability rises rapidly as $\gamma$ moves away from unity - whether individuals overreact or under react to their partner's signals.

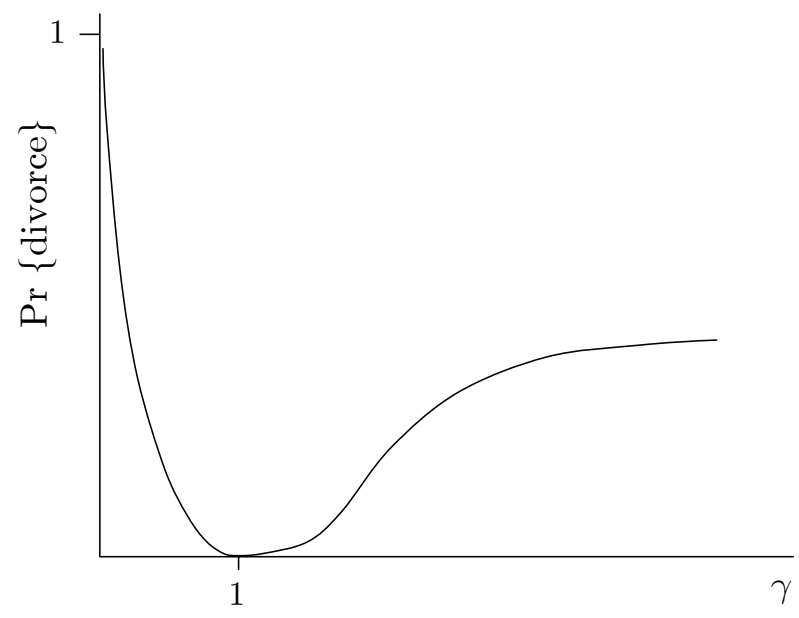

Figure 3. Communication difficulties and the lifetime probability of marital failure. 
Interestingly, overreacting to signals is more damaging to a marriage than is ignoring them. No matter how little attention couples pay to each other's signals, the lifetime probability of marital failure is bounded well below one. In contrast, spouses that consider each other's signals to be almost perfect will almost certainly divorce. Moreover, because both $\omega_{1}^{*} \rightarrow 0$ and $\omega_{2}^{*} \rightarrow 0$ as $\gamma \rightarrow 0$, they are likely to divorce very quickly.

The first passage distribution has only recently been derived:

ThEOREM 2 (Choi and Nam [2003: Theorem 7]). The first passage distribution for $\omega_{1}^{*}>0, \omega_{2}^{*}>0$, and $T>0$ is

$$
\begin{array}{r}
F\left(T \mid \omega_{1}^{*}, \omega_{2}^{*}\right)=1-\int_{-x_{1}}^{x_{1}} d \Phi(s)+\sum_{n=1}^{\infty}\left\{e^{-2 \omega_{1}^{*} \omega_{2}^{*}(2 n-1)^{2}}\left(\int_{-x_{2}}^{x_{2}} d \Phi(s)+\int_{-x_{3}}^{x_{3}} d \Phi(s)\right)\right. \\
\left.-e^{-8 \omega_{1}^{*} \omega_{2}^{*} n^{2}}\left(\int_{-x_{4}}^{x_{4}} d \Phi(s)+\int_{-x_{5}}^{x_{5}} d \Phi(s)\right)\right\},
\end{array}
$$

where $\Phi(s)$ is the standard normal distribution., $\sqrt{T} x_{1}=\omega_{1}^{*}+\omega_{2}^{*} T$, $\sqrt{T} x_{2}=(3-4 n) \omega_{1}^{*}+\omega_{2}^{*} T, \quad \sqrt{T} x_{3}=(4 n-1) \omega_{1}^{*}+\omega_{2}^{*} T, \quad \sqrt{T} x_{4}=(1-4 n) \omega_{1}^{*}+\omega_{2}^{*} T$, and $\sqrt{T} x_{5}=(1+4 n) \omega_{1}^{*}+\omega_{2}^{*} T$.

Obviously, any statements made about $F\left(T \mid \omega_{1}^{*}, \omega_{2}^{*}\right)$ can only be supported by numerical calculations. ${ }^{14}$ Figure 4 plots the divorce hazard, $h(T)=F^{\prime}(T) /(1-F(T))$, for given values of $\omega_{1}^{*}$ and $\omega_{2}^{*}$. Variations in parameter values have little impact on the shape of the hazard, which rises rapidly to a unique maximum, before declining to zero asymptotically. Reductions in either $\omega_{1}^{*}$ or $\omega_{2}^{*}$ simply raise the hazard for all $t>0$.

PROPOSITION 5. The divorce hazard rises monotonically until some time $\tau>0$. Thereafter it declines asymptotically to zero.

14. The terms in the summation tend to zero at the rate $e^{-n^{2}}$, so numerical calculations are particularly accurate. 


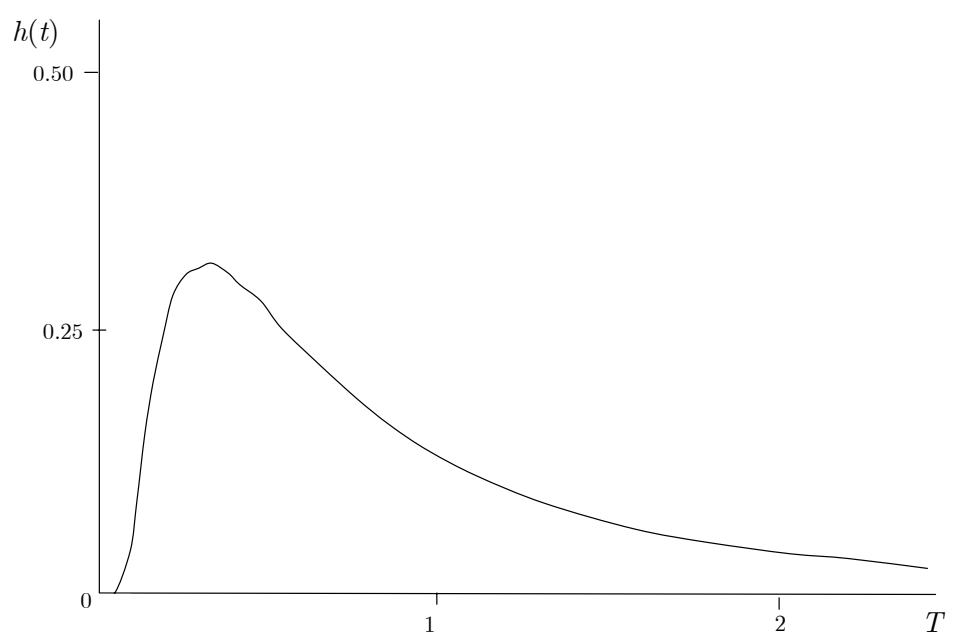

FIGURE 4. Divorce hazard; $\omega_{1}^{*}=\omega_{2}^{*}=1$

For a wide range of parameter values the peak of the hazard comes quite early in a marriage, so when data are coarse studies may only observe a monotonically declining hazard (e.g. Becker, Landes and Michael [1977: Table 3]). But the hazard shape given in the proposition has been found in high-frequency data sets. For example, raw survival data from the National Survey of Family Growth indicates that the US separation hazard peaks sometime in the third year of marriage (Bramlett and Mosher [2001]). Aalen and Gjessing [2001] report the same for Norwegian couples. The pattern survives even after controlling for numerous marriage-specific characteristics. Conditional on earnings, marriage date, and demographic characteristics, Weiss and Willis [1997] find increasing marriage tenure first raises and then lowers the separation hazard in the US, while Svarer [2002] finds the same for Denmark (see Figure 5). ${ }^{15}$

Comparative Statics. In considering the effect of parameter changes on the divorce hazard, it is useful to consider two distinct scenarios. The first, and simplest, is to assess the effect of parameter changes for a single marriage, taking as given the value of the outside

15. Of course, as we know from Jovanovic [1979], this hazard shape is also consistent with models in which couples are learning about the quality of a match. 


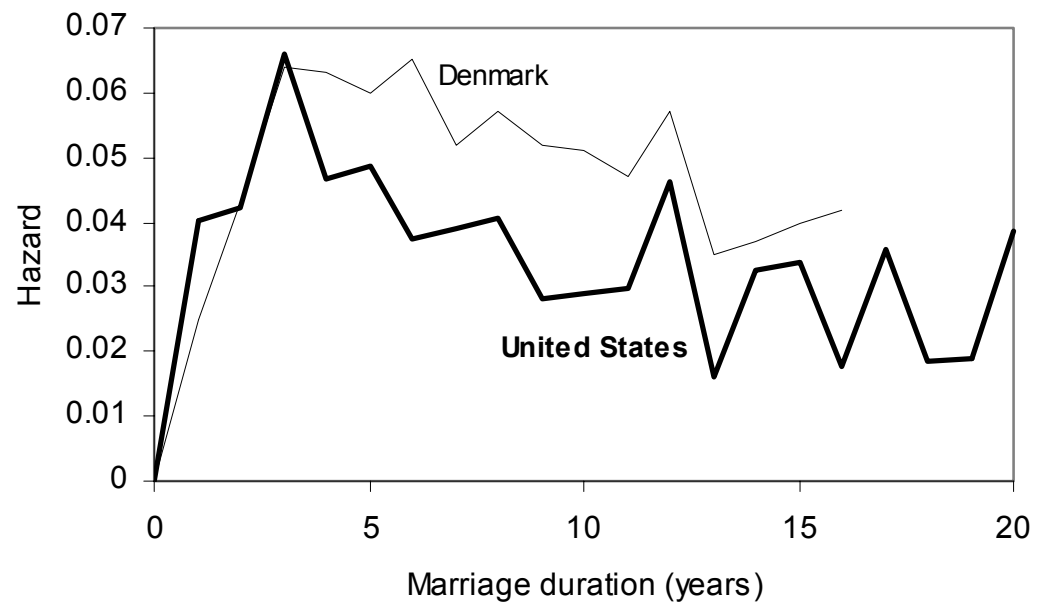

Figure 5. Separation hazards in the US and Denmark. US data are from raw lifetable estimates obtained from a 1995 survey of women aged 15-44 years. Source: Bramlett and Mosher [2001]. The cycles evident in the US data are due to rounding errors in the life tables. Danish data are the baseline hazard obtained from a proportional hazards regression using a sample of individuals followed from 1980 to 1995. Source: Svarer [2002].

option $v-k$. This is equivalent to assuming that parameters are marriage specific, and independent across marriages. The second scenario assumes parameters are common to all marriages, and requires us to assess the effect of parameter changes in society as a whole.

In the first scenario the analysis is straightforward and most parameter changes induce an unambiguously-signed change in the hazard of divorce:

Proposition 6. For a single marriage in a static social environment, (i) the hazard of divorce is strictly increasing in $\sigma_{\theta}^{2}$ and $($ for $\gamma>1) \gamma$, for all $t>0$. (ii) there exists a $0<\tau<\infty$ such that the hazard is strictly decreasing [increasing] in $\sigma_{\zeta}^{2}$ for $t<[>] \tau$.

For given $v-k$, greater prior uncertainty, noisier signals and poorer communication increase the divorce hazard in two ways. First, they increase the hazard of attaining any given size of disagreement. Second, they lead to a decline in the value of a marriage even conditioning on the disagreement, and hence reduce the size of disagreement necessary to 


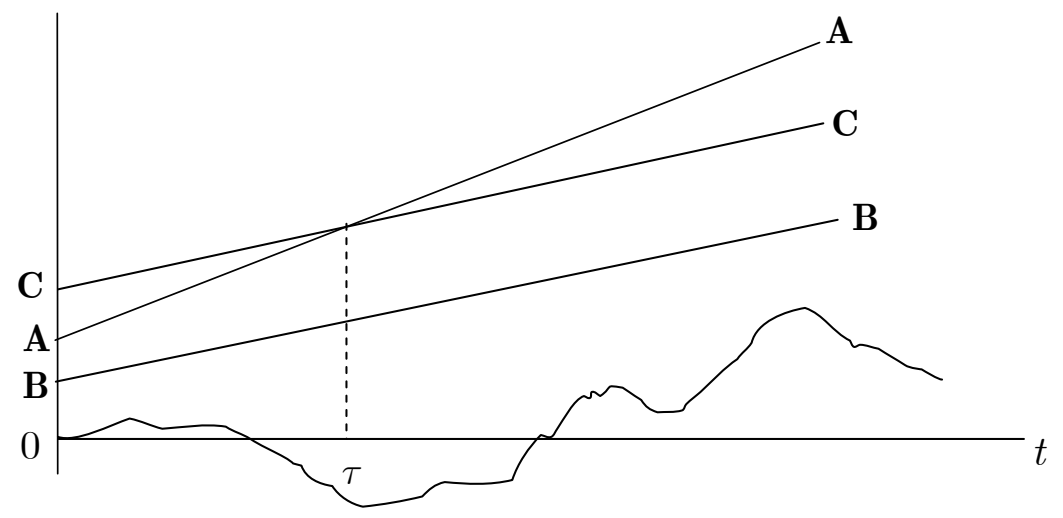

FIGURE 6. Comparative statics. Increases in $\gamma$ and $\sigma_{\theta}^{2}$ shift the boundaries in from $\mathbf{A A}$ to $\mathbf{B B}$. Increases in $\sigma_{\zeta}^{2}$ shift $\mathbf{A A}$ to $\mathbf{C C}$. The lower boundaries (omitted) shift in symmetric fashion.

induce divorce. The time-dependent effects of changes in $\sigma_{\zeta}^{2}$ are also readily explained. On the one hand, an increase in $\sigma_{\zeta}^{2}$ reduces the expected flow of utility while married, because of the concavity of the utility function. On the other hand, it induces both spouses to respond less to all signals, reducing the opportunity for disagreement for any given sequence of signals. The latter effect dominates for $t$ small (see Figure 6).

The second scenario is more complicated. For example, as we have just seen the hazard of divorce is strictly increasing in $\sigma_{\theta}^{2}$ for all $t$ when $v-k$ is fixed. However, $v$ is decreasing in $\sigma_{\theta}^{2}$, and this reduces the hazard at any $t$ by raising the size of disagreement necessary to induce divorce. For young marriages, the former effect dominates and an increase in $\sigma_{\theta}^{2}$ raises the hazard. But as marriage tenure rises, the direct effect of increases in $\sigma_{\theta}^{2}$ are attenuated, while the expected value of becoming single is independent of marriage tenure. Hence, for $t$ large enough, an increase in $\sigma_{\theta}^{2}$ reduces the divorce hazard. However, it is obvious that the following proposition holds:

Proposition 7. The hazard of divorce is strictly increasing in the common social values of $\mu$ and $\lambda$, and it is strictly decreasing in $k$ 
Marital Shocks. It is well-established that significant shocks to the structure of family life increase the divorce hazard and expressions of dissatisfaction. Some shocks, such as the birth of a child, that reduce the hazard of divorce continue to increase expressions of marital dissatisfaction, suggesting that discord in the marriage induced by the shock is dominated by the event's effects on the value of the outside option (see Karney and Bradbury [1995] for a review).

The model provides a natural framework to think about the effect of shocks. Such events alter the target in possibly unknown ways. Assume that for a couple married at time 0 , an unanticipated life-changing event occurs at time $T$. The initial target was a random draw, $\theta$, and couples will on average have made some, possibly significant, progress toward learning it. At $T$, however, the target moves, say from $\theta$ to $\theta+\xi$, where $\xi$ is a draw from $N\left(0, \sigma_{\xi}^{2}\right)$. The event has two effects. Immediately, it lowers the expected current utility from the marriage because the posterior variance over $\theta$ rises from $\sigma_{T}^{2}$ to $\sigma_{T}^{2}+\sigma_{\xi}^{2}$. This will push couples that were already sufficiently close to divorce over the edge. Second, the event alters the future dynamics of disagreement. Increased uncertainty about the true target creates new opportunities to disagree that had, for many couples, essentially disappeared. At each point in time, the hazard of divorce remains higher for couples that experienced a life-changing event than for those that did not, the gap between the two closing only asymptotically.

Figure 7 illustrates the effect of marital shocks at time $T$ on the first passage problem. The boundaries defined by $\omega^{*}(t)$ and $-\omega^{*}(t)$ are shifted in at $T$. Some sample paths for $\omega(t)$ are also illustrated. A couple that found itself at point a at $T$ opts for immediate divorce after the shock. Couples that do not divorce at $T$ nonetheless face increased risk after T. For example, a couple arriving at $\mathbf{b}$ will divorce even though their marriage would have survived absent the shock. Figure 8 illustrates two possible hazard paths. If $\sigma_{\xi}^{2}$ is small relative to $\sigma_{T}^{2}$, the initial increase in the hazard is followed by a monotonically declining path (path $\mathbf{A}$ ). If $\sigma_{\xi}^{2}$ is large relative to $\sigma_{T}^{2}$, the hazard will rise after $T$ before falling again (path $\mathbf{B})$. 


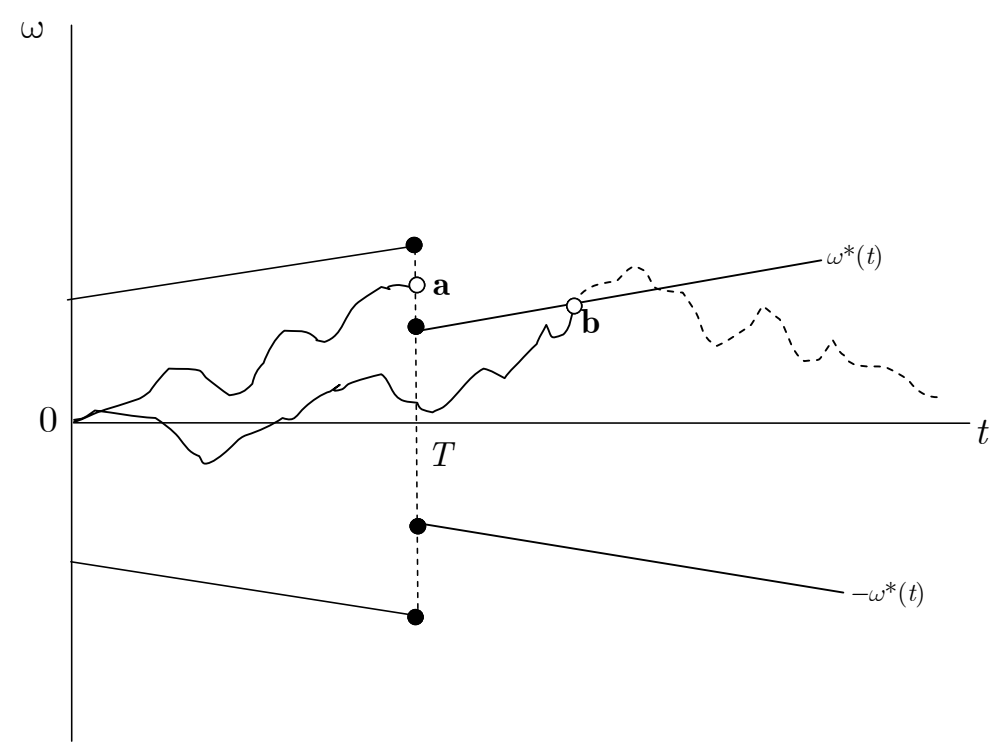

FigURE 7. Marital shocks and the first passage problem.

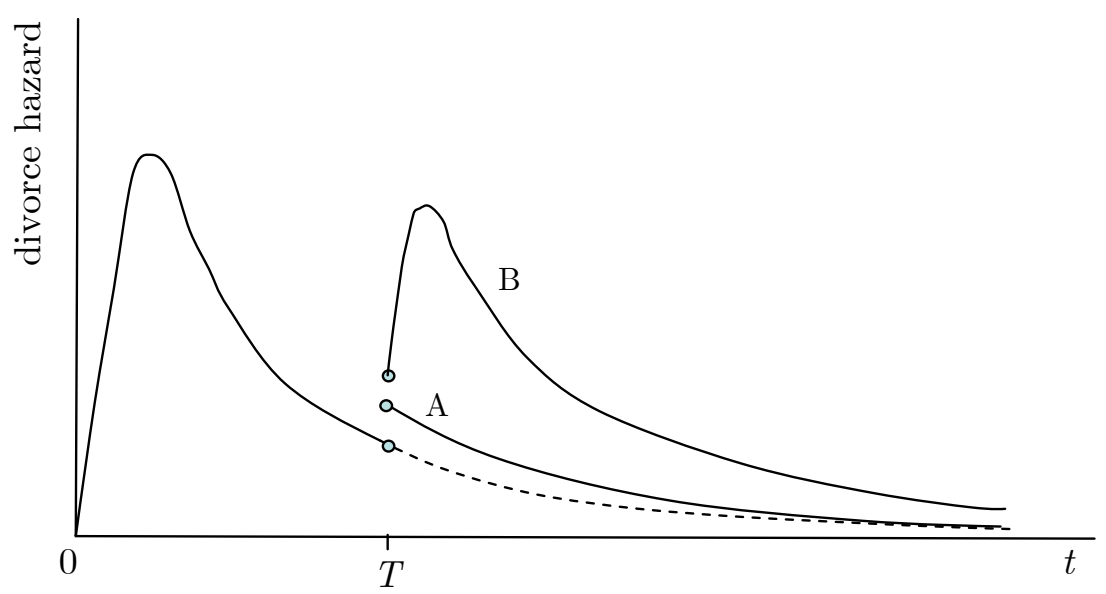

FIGURE 8. Marital shocks and the divorce hazard. 
Welfare. Subject to the constraint that a social planner is unable to make individuals better observers of their spouse's signals, divorce in this framework is efficient. First, under symmetry, divorce is always desired by both parties, so there is no aggrieved party hurt by one spouse's decision to dissolve the marriage. Second, our assumption that the matching function for singles is homogeneous of degree zero in the number of single men and women eliminates any contribution by the newly divorced to the welfare of other singles. The social optimality of private divorce decisions will not hold under asymmetry (Section II.c) or when spouses are solipsistic (Section II.b).

Counseling. If you ask therapists what brings a couple to counseling, communication problems are cited 87 percent of the time, considerably more than any other problem (Whisman, Dixon and Johnson [1997]). But couples seeking counseling typically cite more proximate sources of marital distress, such as parenting, financial, or intimacy issues, and they rate communication problems as less important than do therapists (Doss, Simpson, and Christensen [2004]). Even when communication problems are understood to be a source of distress, they are often expressed in terms of disagreements about more specific issues. The distinction is consistent with the model. It will shortly be shown that couples seek counseling only when they disagree sufficiently (presumably about something). Therapists know that it was communication problems that got the couple to this point. ${ }^{16}$

There is an important distinction between counseling that improves communication and counseling that addresses proximate sources of distress. The former corresponds to a reduction in $\gamma$, which not only reduces the size of the current disagreement, it also influences the future path of $\Delta$ and makes future disagreements less likely. The latter reduces the current size of disagreement, but leaves unaffected the future dynamics of $\Delta$. When counseling focuses on proximate causes, then, its benefits are more likely to fade with time. Empirical evidence appears consistent with this distinction. In a fourth-year follow up of couples receiving one of two distinct types of therapies - behavioral therapy (BT),

16. This divergence of perceptions about the problem extends to a divergence of perceptions about the solution. Therapists use proximate problem solving as a tool to alter behavior. Couples use behavioral counseling as a tool to solve a proximate problem. 
with a relatively greater focus on proximate problem solving, and insight-oriented therapy (IOT), with a relatively greater focus on the underlying intrapersonal dynamics -- Snyder, Willis and Grady-Fletcher [1991] found that 46 percent of couples that had received BT had experienced a significant loss of the short-term gains from counseling, compared with less than 10 percent of couples that had received IOT. Jacobson, Schmaling, and Holtzworth-Munroe [1987] reported deterioration rates of 10 to 30 percent at one year after terminating BT, and 25 to 66 percent after two years.

Since these studies were conducted, BT has evolved, and other models of counseling developed, so that couples are today much more likely to receive counseling that addresses long-term communication difficulties in addition to resolving proximate causes of distress (Gurman and Fraenkel [2002]). Consistent with this evolution, we therefore assume that the effect of counseling is to achieve a reduction in $\gamma$ at cost $c$.

Figure 9, which plots some sample paths for the standard Wiener process, $w(t)$, illustrates the impact of counseling on a couple. In the absence of counseling, the process passing from the origin though points $\mathbf{a}$ and $\mathbf{b}$ illustrates a sample path, while the lines indicated by $\mathbf{A B}$ give the thresholds for $\omega^{*}(t)$. Absent counseling, this couple divorces when they reach point $\mathbf{b}$. But imagine the couple decides to undergo counseling at time $\tau$. Doing so brings about a reduction in $\gamma$, which has two effects. First, it allows the couple to reassess past signals, thereby bringing about a reduction in the current size of disagreement. The resolution of proximate sources of distress shifts the boundaries out to CD. Second, counseling allows couples to process future signals more accurately. This increases the absolute slope of the boundaries (see (12)), which rotate outwards to pass through E. The postcounseling couple experiences a sample path of abcd or abce. If counseling only solved proximate problems (i.e. it reduced the size of the current disagreement without reducing $\gamma)$, this couple would divorce at $\mathbf{c}$. But when counseling addresses communication difficulties, the couple would not divorce until they reach $\mathbf{d}$, or they may instead reach a point such as $\mathbf{e}$, by which time the risk of divorce at some time in the future has become vanishingly small.

It is easy to verify formally the consequences of therapeutic intervention for marriage survival. Because couples receiving counseling are necessarily close to one of the two 


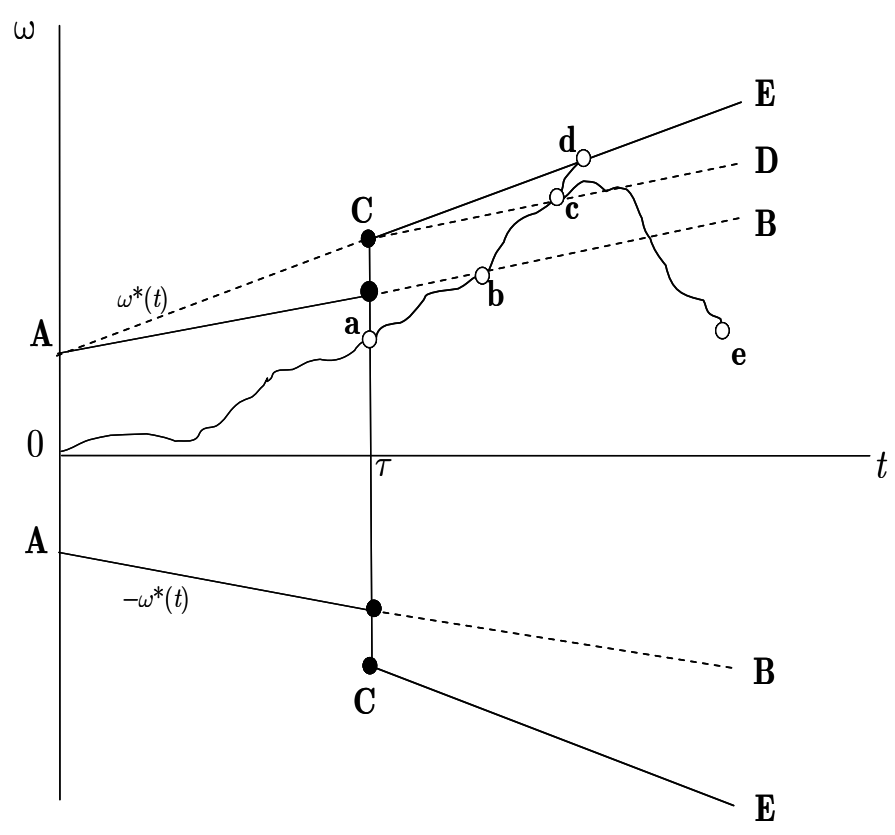

FiguRE 9. The effect of counseling on divorce risk.

boundaries, we can with little loss of accuracy consider the first passage problem as one involving a single linear boundary. Assume this is the upper boundary, such as is indicated by point $\mathbf{a}$ in Figure 9. At $\mathbf{a}$, the couple is a given distance, say $x$, from the boundary. Let the equation of the linear boundary $\mathbf{A B}$ be given by $y=\alpha+\beta(t-\tau)$, so that $x=\alpha-\Delta_{\tau}$. The (defective) density of marriage failure time for any $T \geq \tau$ is then given by the well-known Bachelier-Lévy formula (e.g. Cox and Miller [1965: p.221]) :

$$
f\left(T \mid \alpha, \beta ; \tau, \Delta_{\tau}\right)=\frac{\left(\alpha-\Delta_{\tau}\right)}{\left(2 \pi(T-\tau)^{3}\right)^{1 / 2}} \exp \left\{-\frac{\left(\left(\alpha-\Delta_{\tau}\right)+\beta(T-\tau)\right)^{2}}{2(T-\tau)}\right\} .
$$

Equation (14) gives the density of the survival time after $\tau$ if no counseling is received. Counseling that resolves proximate sources of distress without addressing the underlying communication problems raises $\alpha$, say to $\alpha^{\prime}$, but leaves $\beta$ unchanged. Counseling that 
addresses the underlying communication difficulties raises both parameters, to $\alpha^{\prime}$ and $\beta^{\prime}$. The following first-order stochastic dominance result holds:

Proposition 8. Let $F\left(T \mid \alpha, \beta ; \tau, \Delta_{\tau}\right)$ denote the survival distribution. Then for all $T>\tau, F\left(T \mid \alpha^{\prime}, \beta^{\prime} ; \bullet\right)<F\left(T \mid \alpha^{\prime}, \beta ; \bullet\right)<F(T \mid \alpha, \beta ; \bullet)$.

Proof. Differentiating (14), we have (i) when $\alpha \beta>1, f_{\alpha}<0$ for all $T>\tau$; (ii) when $\alpha \beta<1, f_{\alpha}<0$ for $\tau<T<\alpha^{2}(1-\alpha \beta)^{-1}$ and $f_{\alpha}>0$ otherwise; (iii) $f_{\beta}<0$ for all $T>\tau$.

The foregoing discussion simply assumes a couple chooses counseling at time $\tau$. But who will choose counseling, and when? The simplest case to analyze is that of perfectly efficient intervention, which reduces $\gamma$ to one and eliminates all future marital discord. Assume that a couple with disagreement $\Delta_{t}^{2}$ undergoes counseling. The expected value of the marriage thereafter is

$$
\tilde{V}_{t}-c=-\frac{\sigma_{\zeta}^{2}}{1-\beta}-\sigma_{\theta}^{2} \sigma_{\zeta}^{2} \sum_{i=0}^{\infty} \beta^{i}\left((t+i) \sigma_{\theta}^{2}+\sigma_{\zeta}^{2}\right)^{-1}-c
$$

By assumption $\tilde{V}_{t}>v-k$ for all $t$, and $\tilde{V}_{t}$ is clearly increasing in $t$. Consequently, in a choice between divorce or counseling, there exists a $T$ (possibly zero, possibly infinite), such that divorce is chosen for $t<T$, while counseling is chosen for $t \geq T$. If $c$ is small enough $^{17}$, then $T=0$; if $c$ is large enough ${ }^{18}$, then $T \rightarrow \infty$. It is also straightforward to show in this case that for $t \geq T$ there exists a critical value, $\tilde{D}_{t}^{2} \leq D_{t}^{2}$, such that counseling is sought if and only if $\Delta_{t}^{2} \geq \tilde{D}_{t}^{2} \cdot{ }^{19}$

17. That is, if $c<\tilde{V}_{0}-(v-k)$.

18. That is, if $c>\max _{t}\left\{\tilde{V}_{t}-(v-k)\right\}=-\sigma_{\zeta}^{2} /(1-\beta)-(v-k)$.

19. Simply replace $v-k$ in (8) with $\max \left\{v-k, \tilde{V}_{t}-c\right\}$. Having already established that $V$ is decreasing in $\Delta$, the usual reservation property holds. 
Proposition 9. Couples in distress will choose divorce before counseling if the marriage duration is short, and counseling before divorce if the marriage duration is long.

Proposition 9 is in principle testable, but I am not aware of any evidence on the question. This is perhaps not so surprising, because an empirical test would be encumbered with serious selection problems. First, couples with long marriage duration are less likely to have sufficiently severe problems to warrant counseling, so they will be underrepresented in samples of couples that are or were married. Second, counseling is more likely to have long-term success in older couples, so that in samples of divorced couples those with long marriage duration that sought counseling will again be underrepresented.

\section{B. Solipsistic Spouses}

Solipsistic individuals hold mistaken beliefs about the future evolution of disagreements. From equation (A.1) in the Appendix, disagreements evolve according to the linear stochastic difference equation

$$
\Delta_{i, t+1}=a_{t} \Delta_{i t}+b_{t} z_{i, t+1},
$$

where $z_{i, t+1}=\zeta_{i, t+1}-\zeta_{j, t+1}$ is distributed $N\left(0,2 \sigma_{\zeta}^{2}\right)$. However, a solipsistic individual that underestimates the precision of his spouse's signals believes that $z_{i, t+1}$ is distributed $N\left(0,(1+\gamma) \sigma_{\zeta}^{2}\right)$, and so he believes that $\Delta$ is more variable than it really is. This solipsist's perceived conditional variance of $\Delta_{i, t+1}$ can be obtained from the true conditional variance by a series of mean-preserving spreads. Convexity of the value function then implies that for any given size of disagreement, this solipsist's valuation of marriage exceeds its true valuation. Let $\bar{D}_{t}^{2}$ denote the disagreement size required to induce divorce for this solipsist. Clearly $\bar{D}_{t}^{2}>D_{t}^{2}$.

For overconfident solipsists, who overestimate the precision of their own signals, let $\gamma^{-1} \sigma_{\zeta}^{2}$ denote the solipsist's perceived variance of his own signals. This solipsist believes that $z_{i, t+1}$ is distributed as $N\left(0,\left(\gamma^{-1}+1\right) \sigma_{\zeta}^{2}\right)$, when the true variance is again $2 \sigma_{\zeta}^{2}$. Consequently, this solipsist's valuation of marriage is less than its true valuation. If $\overline{\bar{D}}_{t}^{2}$ denotes the critical disagreement for this solipsist, we have $\overline{\bar{D}}_{t}^{2}<D_{t}^{2}$. 
Depending on the form that solipsism takes, solipsistic individuals may be either too quick or too slow to divorce. When overconfident solipsists choose divorce, doing so is not optimal. When divorce is optimal, solipsists that underestimate the precision of their spouse's signals will delay the decision.

\section{Unequal Partnerships}

Few marriages are symmetric. One partner may have relatively greater difficulties communicating signals, or being understood. Even when communication difficulties are symmetric, one spouse may enjoy greater autonomy, in the sense that the household decision more closely reflects one spouse's beliefs. In this section, it is assumed that, while the extent of communication difficulties is equal between spouses, there is asymmetry because $\phi_{m}>1 / 2>\phi_{f}$. The assumption that greater weight is put on the husband's beliefs is not arbitrary. The evidence cited in the introduction indicates that women are most likely to suffer from an inequitable distribution of decision-making power. At least with respect to the division of household chores, there is also some direct evidence on this matter. A survey assessing perceptions of fairness in the division of household labor produced the following results: for women it lay between "somewhat unfair to me" and "fair to both"; for men it was between "fair to both" and "somewhat unfair to my wife." (Nock and Brinig [2002]).

Asymmetry affects the flow of utility earned in a marriage, and hence the divorce decision. But if asymmetry is a fact of social life rather than a feature peculiar to the current marriage, it also affects the value of being single. If women can expect to have relatively less decision-making power in all marriages then not only will the current marriage be less attractive, so will future marriages. Unhappiness in the current marriage promotes divorce, while the prospect of future unhappy marriages makes divorce less attractive. One should expect, of course, that the former effect dominates in the divorce decision, because of discounting, because divorce is followed by a period of time as a single person, and because new marriages begin with a period of no disagreement. Presuming this to be the case, it is convenient to suppress the second effect of asymmetry by assuming that after divorce remarriage is not possible. That is, the value of becoming single is independent of the degree of asymmetry in marriage. 


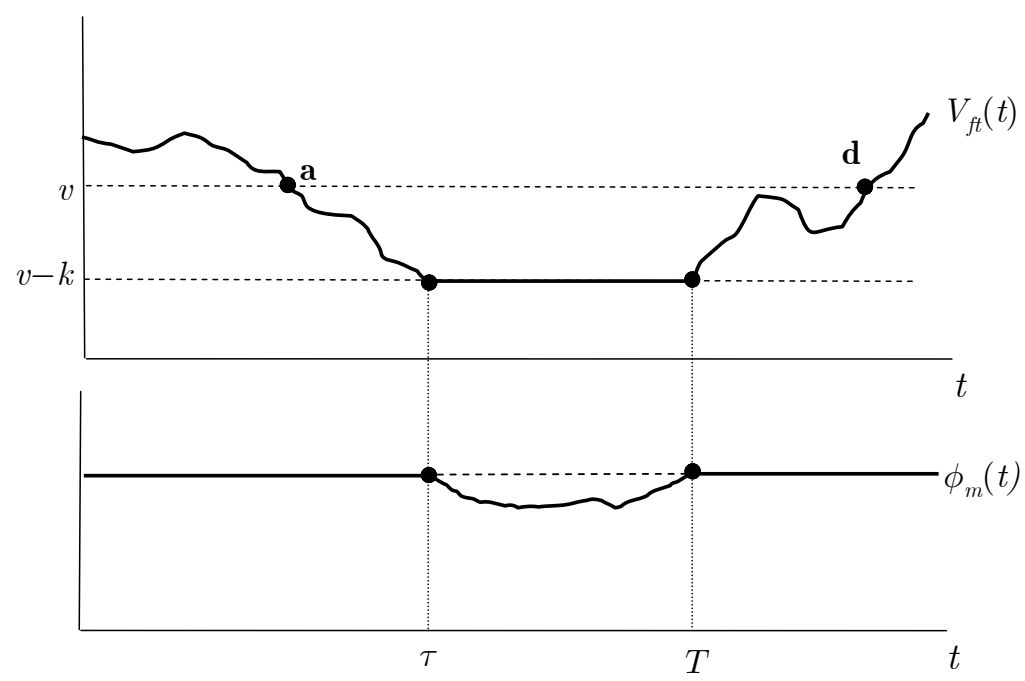

FIGURE 10. Desperate wives and their minimally conciliatory husbands.

Who Chooses Divorce? It is easy to verify that the wife's disagreement with the joint decision, $\Delta_{f}$, is related to her husband's disagreement by $\Delta_{f}=\phi_{m}\left(1-\phi_{m}\right)^{-1} \Delta_{m}$. Thus, for any feasible sample path $\Delta_{m}$, it follows that $\Delta_{f, t+j}^{2} \geq \Delta_{m, t+j}^{2}$ and $E_{f t}\left(u_{t+j}\right) \leq E_{m t}\left(u_{t+j}\right)$ for all $j$, with strict inequality for at least some future time periods. Hence $V_{f}<V_{m}$ and, as $v$ does not depend on $\phi_{m}$, the wife will choose divorce before the husband.

Welfare and the Coasian Solution. If $\phi_{m}$ is fixed, a wife's decision to divorce is not socially optimal, because she fails to take into account her husband's welfare loss from the divorce. But if the husband can transfer utility to his wife by volunteering to reduce $\phi_{m}$, divorce can be made efficient. These are standard results understood since Becker [1973].

It is nevertheless interesting to consider the nature of the conciliatory actions a husband will make. The upper panel of Figure 10 provides a sample path of the value function for a married woman. As time passes, she experiences a deterioration in the quality of the marriage until, at point $\mathbf{a}$, she is no more happy than she was as a single person. But given the cost of divorce, she remains married. After further deterioration to time $\tau$, she becomes indifferent between marriage and divorce. Up to this point, the husband has had no need to accommodate his wife's increasing unhappiness. But after time $t$, divorce can 
be prevented only if the husband surrenders some of his decision-making power. This he does (shown in the lower panel of Figure 10); but he does so only to the extent necessary to maintain his wife at $V_{f t}=v-k$. Eventually, a sufficient amount of disagreement is resolved so that, by time $T$, the husband has fully reverted to type. Only after this point does the wife's valuation of the marriage begin to rise again. During the interval $[\tau, T]$, the wife depicted in Figure 10 is one of the desperate wives of the title: she is as miserable as it is possible to be in a marriage; she is less happy than a single woman; and she knows there is every prospect that this state of affairs will persist for some time to come. ${ }^{20}$

Income Shocks Under Asymmetry. Becker, Landes and Michael [1977] were the first to produce evidence that increases in husbands' incomes reduce the hazard of divorce, while increases in wives' incomes have the opposite effect. Weiss and Willis [1997] showed that these contrary effects of income exist only when the shocks were not predictable at the time of marriage. The standard explanation is that they result from an asymmetric division of labor in the household: wives are more likely to specialize in non-market production (perhaps because only they can bear children; Becker [1973]), so increases in their earnings potential are less important within the marriage than it would be upon divorce, when they would have to rely entirely on their own income.

The labor specialization story has attracted its share of criticism because it allows for specialization between husband and wife while it assumes away labor specialization among women, some of whom would prefer to hire others to do household chores (Brinig and Carborne [1988]). Moreover, there has been only a modest decline in the fraction of household production undertaken by American women since the 1960s, despite large increases in labor force participation (Blau, Ferber and Winkler [1992], Blau [1998]). Using data from the National Survey of Families and Households, Nock and Brinig [2002] point out that even today women account for over two-thirds of the hours worked in household

20. A husband will not always save a marriage in this way. If $\phi_{m}$ falls to $1 / 2$, at any point in the interval $[\tau, T]$, then he chooses to divorce instead of making further concessions. 
production, and this distribution is almost impervious to the amount of work a wife does outside the home.

Income effects can be incorporated in the model in a simple manner by allowing appropriable income to enter the one-period payoffs to spouses and single people in an additive manner. Then, asymmetry in decision-making authority is sufficient to generate an alternative explanation for the contrary impacts of shocks to the incomes of husband and wife. Assume that husband and wife earn the same income, and have the same value of being single. A positive shock to income has two effects. For the individual whose income rises, it makes divorce more attractive. The entire increment to income is available for personal consumption when single, but part of it will be appropriated by the spouse in a continuing marriage. In contrast, marriage becomes more attractive to the spouse because it provides the spouse with a claim over part of the additional income. Then, because a greater fraction of wives than husbands are "close" to choosing divorce, a positive shock to the husband's income may induce more women to remain married than it induces husbands to choose divorce. For the same reason, a positive shock to the wife's income may induce more women to divorce than it induces men to remain married. This is a possibility, rather than a general implication of the model. But it does seem to be a likely outcome for modest income shocks if there is a sufficient degree of asymmetry in decision-making power.

By way of illustration, Figure 11 plots the densities of the squared disagreement with the joint household decision by husband and wife at time $t$, each conditional on the couple still being married at time $t-1 .^{21}$ The density of $\Delta_{f t}^{2}$ is shifted to the right of the density of $\Delta_{m t}^{2}$, because $\Delta_{f t}^{2}=\phi_{m}^{2}\left(1-\phi_{m}\right)^{-2} \Delta_{m t}^{2}$ and $\phi_{m}>1 / 2$. Let $D_{t}^{2}$ denote the critical threshold for divorce, and for simplicity assume it is the same for husband and wife. In the absence of shocks to income, all couples for whom $\Delta_{f t}^{2}>D_{t}^{2}$ will divorce in period $t$. An increment to one's own income reduces the size of disagreement necessary for divorce, say to $D_{t}^{2}-\delta$. An increment to one's spouse's income raises $D_{t}^{2}$ to, say, $D_{t}^{2}+\delta^{\prime}$. Thus, when a

21. It is possible to construct the exact conditional density for $\Delta_{t}^{2}$, using the concept of the Brownian bridge (c.f. Choi and Nam [2003; section 3.2]). However, the result is complicated, and it does not eliminate the essential ambiguity illustrated heuristically here. 


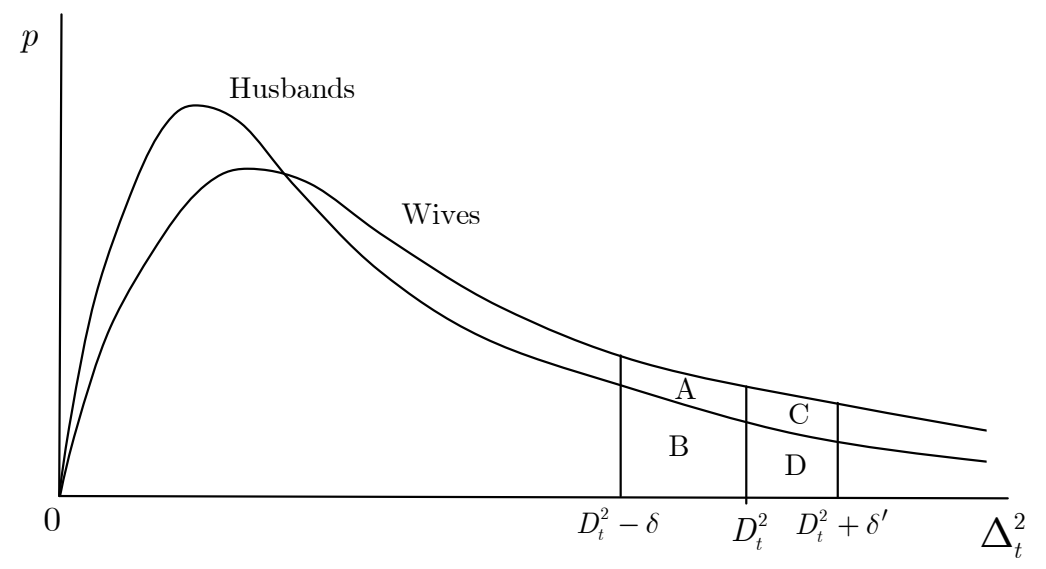

Figure 11. Densities of squared disagreements at time $t$, conditional on still being married at time $t-1$.

husband's income rises, an additional percentage of wives, indicated by $\mathrm{C}+\mathrm{D}$ choose not to divorce, while a fraction $\mathrm{B}$ of husbands now find divorce attractive. In contrast, an increase in the wife's income induces an additional fraction $\mathrm{A}+\mathrm{B}$ of women to seek divorce while inducing an additional fraction D of men to remain married. Generating the observed effects of income shocks requires only that $B-D<C$. Smoothness of the density functions ensures that this must be the case for small enough income shocks. ${ }^{22}$

\section{Conclusions}

Motivated by extensive empirical evidence that communication difficulties are a pervasive source of marital distress and failure, this paper presented a model in which communication takes center stage. Couples embark upon married life uncertain about the joint decisions they need to make. The optimal decisions are slowly revealed to them through noisy, private signals. A notable feature of the model is that uncertainty does not itself

22. The reverse can never be true. For a positive shock to the husband's [wife's] income to raise [lower] the divorce hazard requires that $\mathrm{C}<\mathrm{B}-\mathrm{D}<-\mathrm{A}$, which is impossible. 
induce marital failure, even though it affects utility during a marriage. Instead, marriages suffer distress, and possibly dissolution, because spouses cannot accurately process their partner's private signals. When private signals diverge, spouses also disagree about the joint decisions, and some will do so strongly enough to prefer divorce.

Much of the analysis has been concerned with the mechanics behind the evolution of marital distress and the divorce hazard. But the model also offers some insights about the welfare properties of divorce decisions, and the effect of interventions such as marital therapy. Whether the divorce decision is efficient depends upon the reasons underlying communication difficulties and whether the marriage is symmetric. If well-intentioned spouses simply have difficulty observing each other's signals, then under symmetry private divorce decisions are optimal. But some individuals, whom we have called solipsists, may choose to discount the accuracy of their spouse's signals or overestimate the accuracy of their own signals, even though they could avoid doing so with a little introspection. For marriages involving solipsists, the divorce decision is not optimal.

Asymmetry, for example in decision-making power, also induces inefficiency in divorce decisions. But in this case, there exists a Coasian solution in which individuals that prefer to stay married can compensate their spouses for foregoing divorce by surrendering some decision-making power. Empirical evidence favors the assumption that husbands typically hold the greater share of decision-making power and they will be the ones required to surrender some of it if the marriage becomes distressed. Unfortunately, the best that a husband can credibly offer to is to maintain his wife in a situation of desperation: she will remain, for possibly an extended period of time, the most miserable that a spouse can be and yet not initiate divorce.

Throughout, it has been assumed that all marriages are ex ante identical. But, of course, some marriages that fail result from poor matches that no amount of communication can overcome. Some divorces would then arise because of poor matches, while others would arise because of poor communication. Combining heterogeneous match quality with communication difficulties in a single model is, of course, feasible, but it seems that doing so would provide few insights. One exception is in the role of counseling, which would tend to "save" marriages that are worth saving, and encourage divorce in marriages that should be dissolved. 


\section{Appendix}

Proof of Proposition 1. To establish that $V\left(\Delta_{i t}^{2}, t ; v-k\right)$ is strictly decreasing in $\Delta_{i t}^{2}$, we need two lemmas. To simplify notation, we let $x=\Delta_{i t}^{2}, x^{\prime}=\Delta_{i, t+1}^{2}$.

LEMma 1. $F\left(x^{\prime} \mid x ; t\right)$ is decreasing in $x$ for all $t$ and $x^{\prime}>0$.

PROOF. Updating (4) by one period and rearranging yields

$$
\Delta_{i, t+1}=\left[\frac{(\gamma+1) t \sigma_{\theta}^{2}+\gamma \sigma_{\zeta}^{2}}{(\gamma+1)(t+1) \sigma_{\theta}^{2}+\gamma \sigma_{\zeta}^{2}}\right] \Delta_{i t}+\left[\frac{(\gamma-1) \sigma_{\theta}^{2}}{2\left((\gamma+1)(t+1) \sigma_{\theta}^{2}+\gamma \sigma_{\zeta}^{2}\right)}\right] z_{i, t+1}
$$

where $z_{i, t+1}=\zeta_{i, t+1}-\zeta_{j, t+1} \quad$ is distributed $N\left(0,2 \sigma_{\zeta}^{2}\right)$. Thus, conditional on $\Delta_{i t}$, $\Delta_{i, t+1} \sim N\left(a_{t+1} \Delta_{i t}, 2 \sigma_{\zeta}^{2} b_{t+1}^{2}\right)$, where $a_{t+1}$ and $b_{t+1}$ are respectively the first and second terms in square brackets in (A.1). Define $\tilde{\Delta}_{i, t+1}=\left(\sqrt{2} \sigma_{\zeta} b_{t+1}\right)^{-1} \Delta_{i, t+1}$, so that $\tilde{\Delta}_{i, t+1} \sim N\left(\lambda_{t}^{1 / 2} \Delta_{i t}, 1\right)$ where $\lambda_{t}^{1 / 2}=a_{t+1}\left(\sqrt{2} \sigma_{\zeta} b_{t+1}\right)^{-1}$. Let $\tilde{x}^{\prime}=\tilde{\Delta}_{i, t+1}^{2}$. Its conditional distribution is $\tilde{x}^{\prime} \sim \chi_{(1)}^{1}\left(\lambda_{t} x\right)$; that is, a non-central chi-square distribution with one degree of freedom and location parameter $\lambda_{t} x$, defined by

$$
F\left(\tilde{x}^{\prime} \mid x ; t\right)=\sum_{j=0}^{\infty} \frac{e^{-\lambda x / 2}(\lambda x)^{j}}{j !} \operatorname{Pr}\left(\chi_{1+2 j}^{2} \leq \tilde{x}^{\prime}\right)
$$

where $\operatorname{Pr}\left(\chi_{1+2 j}^{2} \leq \tilde{x}^{\prime}\right)$ is the cdf of a (central) chi-square distribution with $1+2 j$ degrees of freedom (Johnson, Kotz and Balakrishnan [1995, p. 435]). It is a standard property of the non-central chisquare distribution that $\operatorname{Pr}\left[\chi_{(1)}^{1}\left(\lambda_{t} x\right)<\tilde{x}^{\prime}\right]$ is strictly decreasing in the location parameter for all $\tilde{x}^{\prime}>0$ (e.g. Ghosh [1970]). As $x \propto \tilde{x}$ for any fixed $t$, it follows that $F\left(x^{\prime} \mid x ; t\right)$ is strictly decreasing in $x$ for all $x^{\prime}>0$.

Lemma 2. Let $T V\left(x^{\prime}, t+1\right)=\max \left\{v-k, u(x)+\beta \int V\left(x^{\prime}, t+1\right) d F\left(x^{\prime} \mid x ; t\right)\right\}$ denote the operator defined in (8). $T V\left(x^{\prime}, t+1\right)$ (i) maps bounded continuous functions into bounded continuous functions, and (ii) is a contraction mapping.

ProOF. (i) $V$ is bounded from above by $-\sigma_{\zeta}^{2} /(1-\beta)$ (a marriage with no disagreement lasting forever) and from below by $v-k$. The conditional distribution $F$ is explicitly defined in Lemma 1 
and has the Feller property. Hence, if $V\left(x^{\prime}, t+1\right) \in\left[v-k, \sigma_{\zeta}^{2} /(1-\beta)\right]$ and is continuous, $\int V\left(x^{\prime}, t+1\right) d F\left(x^{\prime} \mid x, t\right)$ has the same property. Then as $u(x)<0$ and is continuous in $x, T V$ is also a bounded continuous function. (ii) Given the properties described in part (i), standard application of Blackwell's Theorem establishes that $T V$ is a contraction mapping. •

We can now establish that $V(x, t)$ is strictly decreasing in $x$ for all $V>v-k$. Let $g(x, t)$ be a bounded function, continuous in $x$ for any $t$. Let $\hat{x}_{t}$ denote the value of $x$ such that $g\left(\hat{x}_{t}, t\right)=v$, and assume that $g(x, t)$ is strictly decreasing in $x$, for $x<\hat{x}_{t}$. Then

$$
\begin{aligned}
\operatorname{Tg}\left(x^{\prime}, t+1\right) & =\max \left\{v-k, u(x)+\beta \int g\left(x^{\prime}, t+1\right) d F\left(x^{\prime} \mid x ; t\right)\right\} \\
& =\max \left\{v-k, u(x)+\beta(v-k)\left(1-F\left(\hat{x}_{t+1} \mid x ; t\right)\right)+\beta \int_{0}^{\hat{x}_{t+1}} g\left(x^{\prime}, t+1\right) d F\left(x^{\prime} \mid x ; t\right)\right\} .
\end{aligned}
$$

Integrating the last term in (A.2) by parts yields $\beta(v-k) F\left(\hat{x}_{t+1} \mid x ; t\right)-\beta \int_{0}^{\hat{x}_{t+1}} g_{x^{\prime}} F\left(x^{\prime} \mid x ; t\right) d x^{\prime}$, where $g_{x^{\prime}}=\partial g / \partial x^{\prime}$, and hence

$$
T g\left(x^{\prime}, t+1\right)=\max \left\{v-k, u(x)+\beta v-\beta \int_{0}^{\hat{x}_{t+1}} g_{x^{\prime}}\left(x^{\prime}, t+1\right) F\left(x^{\prime} \mid x ; t\right) d x^{\prime}\right\} .
$$

Differentiating (A.3) with respect to $x$ yields

$$
\frac{d}{d x}\left\{T g\left(x^{\prime}, t+1\right)\right\}=\left\{\begin{array}{ll}
u_{x}-\beta \int_{0}^{\hat{x}_{t+1}} g_{x^{\prime}}\left(x^{\prime}, t+1\right) F_{x}\left(x^{\prime} \mid x ; t\right) d x^{\prime}<0, & \text { if } T g\left(x^{\prime}, t+1\right)>v-k \\
0, & \text { if } T g\left(x^{\prime}, t+1\right) \leq v-k
\end{array},\right.
$$

where the inequality makes use of Lemma 1. Hence, if $g\left(x^{\prime}, t+1\right)$ is strictly decreasing in $x$, for $x<\hat{x}_{t+1}$, then $T g\left(x^{\prime}, t+1\right)$ is strictly decreasing in $x$, for $x<\hat{x}_{t}$. By induction, $T^{n} g\left(x^{\prime}, t+1\right)$ is also decreasing in $x$, for $x<\hat{x}_{t}$. But from Lemma $2 T$ is a contraction mapping, so $\lim _{n \rightarrow \infty} T^{n} g\left(x^{\prime}, t+1\right)=V(x, t) \equiv V\left(\Delta_{i t}^{2}, t, v-k\right)$. Hence $V$ is decreasing in $\Delta_{i t}^{2}$. •

The Reservation Equation. When $\Delta_{t}^{2}=D_{t}^{2}$, equation (8) implies

$$
\begin{aligned}
v-k & =E_{t}\left(u\left(D_{t}^{2}\right), t\right)+\beta \int V\left(\Delta_{t+1}^{2}, t+1 ; v-k\right) d F\left(\Delta_{t+1}^{2} \mid D_{t}^{2}, t\right) \\
& =E_{t}\left(u\left(D_{t}^{2}\right), t\right)+\beta(v-k)\left(1-F\left(D_{t+1}^{2} \mid D_{t}^{2}, t\right)\right)+\beta \int V\left(\Delta_{t+1}^{2}, t+1 ; v-k\right) d F\left(\Delta_{t+1}^{2} \mid D_{t}^{2}, t\right) .
\end{aligned}
$$


Integrating by parts,

$$
\begin{gathered}
(1-\beta)(v-k)=E_{t}\left(u\left(D_{t}^{2}\right), t\right)-\beta F\left(D_{t+1}^{2} \mid D_{t}^{2}, t\right)+\beta V\left(D_{t+1}^{2} \mid D_{t}^{2}, t\right) F\left(D_{t+1}^{2}\right) \\
\quad-\beta \int_{0}^{D_{t+1}^{2}} V_{\Delta^{2}}\left(\Delta_{t+1}^{2}, t+1 ; v-k\right) F\left(\Delta_{t+1}^{2} \mid D_{t}^{2}, t\right) d \Delta_{t+1}^{2} \\
=E_{t}\left(u\left(D_{t}^{2}\right), t\right)-\beta \int_{0}^{D_{t+1}^{2}} V_{\Delta^{2}}\left(\Delta_{t+1}^{2}, t+1 ; v-k\right) F\left(\Delta_{t+1}^{2} \mid D_{t}^{2}, t\right) d \Delta_{t+1}^{2},
\end{gathered}
$$

where use was made of the fact that $V\left(\Delta_{t}^{2}\right)=v-k$ for all $\Delta_{t}^{2} \geq D_{t}^{2}$.

Proof of Proposition 2. It is only necessary to establish that the value function is linear in $\Delta_{t}^{2}$ when divorce is not an option. In this case the value function is

$$
W\left(\Delta_{t}^{2}, t\right)=-\sigma_{\zeta}^{2}\left(1+\frac{\gamma \sigma_{\theta}^{2}}{(\gamma+1) t \sigma_{\theta}^{2}+\gamma \sigma_{\zeta}^{2}}\right)-\Delta_{t}^{2}+\beta \int W\left(\Delta_{t+1}^{2}, t+1\right) d F\left(\Delta_{t+1}^{2} \mid \Delta_{t}^{2}, t\right) .
$$

Assume $W\left(\Delta_{t}^{2}, t\right)=A_{t}+B_{t} \Delta_{t}^{2}$ for some sequence $\left\{A_{t}, B_{t}\right\}$. Substituting the proposed solution into (A.5) yields

$$
A_{t}+B_{t} \Delta_{t}^{2}=-\sigma_{\zeta}^{2}\left(1+\frac{\gamma \sigma_{\theta}^{2}}{(\gamma+1) t \sigma_{\theta}^{2}+\gamma \sigma_{\zeta}^{2}}\right)-\Delta_{t}^{2}+\beta A_{t+1}+\beta B_{t+1} E\left[\Delta_{t+1}^{2} \mid \Delta_{t}^{2}, t\right]
$$

From (A.1),

$$
E\left[\Delta_{t+1}^{2} \mid \Delta_{t}^{2}, t\right]=\left(\frac{(\gamma+1) t \sigma_{\theta}^{2}+\gamma \sigma_{\zeta}^{2}}{(\gamma+1)(t+1) \sigma_{\theta}^{2}+\gamma \sigma_{\zeta}^{2}}\right)^{2} \Delta_{t}^{2}+\sigma_{\zeta}^{2}\left(\frac{(\gamma-1) \sigma_{\theta}^{2}}{2\left((\gamma+1)(t+1) \sigma_{\theta}^{2}+\gamma \sigma_{\zeta}^{2}\right)}\right)^{2} .
$$

Substituting (A.7) into (A.6) and collecting terms yields a pair of difference equations in the unknown coefficients:

$$
\begin{aligned}
& B_{t}=-1+\beta\left(\frac{(\gamma+1) t \sigma_{\theta}^{2}+\gamma \sigma_{\zeta}^{2}}{(\gamma+1)(t+1) \sigma_{\theta}^{2}+\gamma \sigma_{\zeta}^{2}}\right)^{2} B_{t+1}, \\
& A_{t}=\beta A_{t+1}+\beta \sigma_{\zeta}^{2}\left(\frac{(\gamma-1) \sigma_{\theta}^{2}}{2\left((\gamma+1)(t+1) \sigma_{\theta}^{2}+\gamma \sigma_{\zeta}^{2}\right)}\right) B_{t+1}-\sigma_{\zeta}^{2}\left(1+\frac{\gamma \sigma_{\theta}^{2}}{(\gamma+1) t \sigma_{\theta}^{2}+\gamma \sigma_{\zeta}^{2}}\right) .
\end{aligned}
$$

The coefficients on $B_{t+1}$ in (A.8) and on $A_{t+1}$ in (A.9) lie in the interval $(0,1)$ so that the solutions to the difference equations in (A.8) and (A.9) are unique and well-defined as long as the 
boundary conditions are finite. Now $\lim _{t \rightarrow \infty} B_{t+1}=B_{t}$, and (A.8) yields $\lim _{t \rightarrow \infty} B_{t}=1 /(1-\beta)$. Similarly, taking the limit in (A.9) yields $\lim _{t \rightarrow \infty} A_{t}=-\sigma_{\zeta}^{2} /(1-\beta)$. As the solutions are welldefined, it has been established that $W\left(\Delta_{t}^{2}, t\right)$ is linear in $\Delta_{t}^{2}$. But if $W$ is linear, then $V\left(\Delta_{t}^{2}, t\right)$ is convex, as this is a standard property of optimal stopping problems.

\section{References}

Aalen, Odd O., Håkon K. Gjessing (2001): "Understanding the shape of the hazard rate: A process point of view." Statistical Science, 16(1):1-22.

Amato, P.R. (1996): "Explaining the intergenerational transmission of divorce." Journal of Marriage and the Family, 58:628-640.

Amato, P.R., and S.J. Rogers (1997): "A longitudinal study of marital problems and subsequent divorce." Journal of Marriage and the Family, 59:612-624.

Anderson, L.R., and Charles A. Holt (1996): "Information cascades in the laboratory." American Economic Review, 87(5):847-862.

Aumann, Robert J. (1976): "Agreeing to disagree." Annals of Statistics, 4:1236-1239.

Becker, Gary S. (1973): "A theory of marriage: Part I." Journal of Political Economy, 81(4):813846.

Becker, Gary S. (1974): "A theory of marriage: Part II." Journal of Political Economy, 82(2):S11S26.

Becker, Gary S., Elisabeth M. Landes, and Robert T. Michael (1977): "An economic analysis of marital instability." Journal of Political Economy, 85(6):1141-1188.

Bramlett, Matthew D., and William D. Mosher (2001): "First marriage dissolution, divorce, and remarriage: United States." Advance data from vital and health statistics, no. 323. Hyattsville, MD: National Center for Health Statistics.

Blau, Francine D. (1998): "Trends in the well-being of American women: 1970-1995." Journal of Economic Literature, 36(1):112-165.

Blau, Francine D., Marianne A. Ferber, and Anne E. Winkler (1992): The Economics of Women, Men, and Work. Englewood Cliffs, NJ: Prentice-Hall.

Bougheas, Spiros, and Yannis Georgellis (1999): "The effect of divorce costs on marriage formation and dissolution." Journal of Population Economics, 12:489-498.

Brinig, Margaret F., and Douglas W. Allen (2000): "These boots are made for walking: Why most divorce filers are women." American Law and Economics Review 2(1):126-169.

Brinig, Margaret F., and June Carborne (1988): "The reliance interest in marriage and divorce." Tulane Law Review, 62:853-905.

Burdett, Kenneth, and Melvyn G. Coles (1999): "Long-term partnership formation: Marriage and employment." The Economic Journal, 109 (456):F307-F334. 
Busenitz, L.W., and J.B. Barney (1997): "Differences between entrepreneurs and managers in large organizations: Biases and heuristics in strategic decision-making." Journal of Business Venturing, 12(1):9-30.

Chen, Qi, and Wei Jiang (2003): “Analysts' weighting of private and public information." Manuscript, Duke University.

Chiappori, Pierre Andre and Yoram Weiss (2003): "Marriage contracts and divorce: An equilibrium analysis." Manuscript, University of Chicago.

Choi, Changsun, and Dougu Nam (2003): "Some boundary-crossing results for linear diffusion processes." Statistic and Probability Letters, 62:281-291.

Cooper, Arnold C., Carolyn Y. Woo, and William C. Dunkelberg (1988): "Entreprenuers' perceived chances for success." Journal of Business Venturing, 3:97-108.

Cornelius, Tracy J. (2002): "A search model of marriage and divorce." Review of Economic Dynamics, 6:135-155.

Cox, David R., and H.D. Miller (1965): The Theory of Stochastic Processes. New York: Wiley.

Daniel, Kent, David Hirshleifer, and Avinidhar Subrahmanyam (1998): "A theory of overconfidence, self-attribution, and security market under- and over-reactions." Journal of Finance, 53(5):1839-1886.

DeBondt, W.M., and Richard H. Thaler (1995): "Financial decision-making in markets and firms: A behavioral perspective." In R. Jarrow, et al. (eds.) Finance, Amsterdam: Elsevier.

Doob, J.L. (1949): "Heuristic approach to the Kolmogorov-Smirnov theorems." Annals of Mathematical Statistics, 20(3):393-403.

Doss, Brian D., Lorelei E. Simpson, and Andrew Christensen (2004): "Why do couples seek marital therapy?" Professional Psychology: Research and Practice. 35(6):608-614.

Dowling, Ralph E., and Lyle J. Flint (1990): "The argumentativeness scale: Problems and promise." Communication Studies, 41:183-198.

Elster, Jon (1998): "Emotions and economic theory." Journal of Economic Literature, 36(1):47-74.

Geanakoplos, John D., and Heraklis M. Polemarcharkis (1982): "We can’t disagree forever." Journal of Economic Theory, 28:192-200.

Ghosh, B.K. (1973): "Some monotonicity theorems for $\chi^{2}, F$ and $t$ distributions with applications." Journal of the Royal Statistical Society Series B, 35(3):480-492.

Glass, Shirley P., and Thomas L. Wright: (1985): "Sex differences in type of extramarital involvement and marital dissatisfaction." Sex Roles, 12(9-10):1101-1120.

Gottman, John M. (1994): What Predicts Divorce? The Relationship Between Marital Process and Marital Outcomes. Mahwah, NJ: Laurence Erlbaum.

Greenstein, T.N. (1990): "Marital disruption and the employment of married women." Journal of Marriage and the Family, 52:657-676.

Gurman, Alan S., and Peter Fraenkel (2002): "The history of couple therapy: A millennial review." Family Process, 41(2):199-260. 
Hawkins, James L., Carol Weisberg, and Dixie W. Ray (1980): "Spouse differences in communication style: Preference, perception, behavior." Journal of Marriage and the Family, 12:585-593.

Henry, Ryan G., and Richard B. Miller (2004): "Marital problems occurring in midlife: Implications for couples therapists." American Journal of Family Therapy, 32:405-417.

Infante, Dominic A., and Andrew S. Rancer (1982): "A conceptualization and measure of argumentativeness." Journal of Personality Assessment, 46(1):72-80.

Jacobson, N.S., K.B. Schmaling, and A. Holtzworth-Munroe (1987): "Component analysis of behavioral marital therapy: Two year follow-up and prediction of relapse." Journal of Marital and Family Therapy, 13:187-195.

Johnson, Norman L., Samuel Kotz, and N. Balakrishnan (1995): Continuous Univariate Distributions, Volume 2. New York: John Wiley \& Sons.

Jovanovic, Boyan (1979): "Job matching and the theory of turnover." Journal of Political Economy, 87(5, part1):972-990.

Karney, Benjamin R., and Thomas N. Bradbury (1995): "The longitudinal course of marital quality and stability: A review of theory, method, and research." Psychological Bulletin, 118(1):3-34.

Klepper and Thompson (2006): "Spinoff entry in high-tech industries: Motives and consequences." In Franco Malerba and Stefano Brusoni (eds.) Economic Perspectives on Innovation, Cambridge: Cambridge University Press. In Press.

Komarovsky, Mirra (1964): Blue-Collar Marriage. New York: Vintage.

Kunda, Ziva (1987): "Motivated inference: Self-serving generation and evaluation of causal theories." Journal of Personality and Social Psychology, 53:636-647.

Levenson, R.W., L.L. Carstensen, and J.M. Gottman (1993): "Long-term marriages: Age, gender, and satisfaction." Psychology and Aging, 8:301-313.

Loewenstein, George (2000): "Emotions in economic theory and economic behavior." American Economic Review, 90(2):426-432.

Lundberg, Shelley, and Robert A. Pollack (1993): "Separate-spheres bargaining and the marriage market." Journal of Political Economy, 101(6):988-1010.

McElroy, Marjorie B., and Mary Jean Horney (1981): "Nash-bargained household decisions: Toward a generalization of the theory of demand." International Economic Review, 22:333-49.

Manser, Marilyn, and Murray Brown (1980): "Marriage and household decision-making: A bargaining analysis." International Economic Review, 21:(1):31-44.

Miller, R.B., J.B. Yorgason, J.G. Sandberg, and M.B. White (2003): "Problems that couples bring to therapy: A view across the family life cycle." American Journal of Family Therapy, 31:395407.

Mortensen, Dale (1988): "Matching: Finding a partner for life or otherwise." American Journal of Sociology, 94:S215-S240

Nock, Steven L., and Margaret F. Brinig (2002): "Weak men and disorderly women: Divorce and the division of labor." In Anthony W. Dnes and Robert Rowthorn (eds.) The Law and Economics of Marriage and Divorce. Cambridge: Cambridge University Press, pp. 171-190. 
Odean, Terence (1998): "Volume, volatility, price and profit when all trades are above average." Journal of Finance, 53(6):1887-1934.

Russo, J. Edward, and Paul J. Schoemaker (1992): "Managing overconfidence." Sloan Management Review, 33(1):7-17.

Sahib, Padma R., and Xinhua Gu (2002): "Living in sin and marriage: A matching model." Journal of Population Economics, 15(2):261-282.

Snyder, Douglas K., Robert M. Wills,, and Arveta Grady-Fletcher (1991): "Long-term effectiveness of behavioral versus insight-oriented marital therapy: A 4-year follow-up study." Journal of Consulting and Clinical Psychology, 59(1):138-141.

Stevenson, Betsey, and Justin Wolfers (2006): "Bargaining in the shadow of the law: Divorce laws and family distress." Quarterly Journal of Economics, forthcoming.

Storaasli, R.D., and H.J. Markman (1990): "Relationship problems in the early stages of marriage: A longitudinal investigation." Journal of Family Psychology, 4(1):80-98.

Stutzer, Alois, and Burno S. Frey (2003): "Does marriage make people happy, or do happy people get married?" Institute for Empirical Research in Economics, University of Zurich, working paper no. 143 .

Svarer, Michael (2002): "Determinants of divorce in Denmark." Working paper, University of Aarhus.

Weinstein, Neil D. (1980): "Unrealistic optimism about future life events." Journal of Personality and Social Psychology, 39:806-820.

Weiss, Yoram (1997): "The formation and dissolution of families: Why marry? Who marries whom? And what happens upon divorce." In Mark R. Rosenzweig and Oded Stark (eds.), Handbook of Population and Family Economics, Vol. 1A, pp. 81-123. Amsterdam: Elsevier.

Weiss, Yoram (forthcoming): "Marriage and divorce." In Stephen Durlauf and Lawrence Blume (eds.), New Palgrave Dictionary of Economics, 2" edition. London: Macmillan.

Weiss, Yoram, and Robert J. Willis (1997): "Match quality, new information, and marital dissolution." Journal of Labor Economics, 15(1, part 2):S293-S329.

Whisman, A.F., A.E. Dixon, and B. Johnson (1997): "Therapists' perspectives of couple problems and treatment issues in couple therapy." Journal of Family Psychology, 11:361-366.

Wolcott, Ilene, and Jody Hughes (1999): "Towards understanding the reasons for divorce." Working Paper no. 20, Australian Institute of Family Studies. 